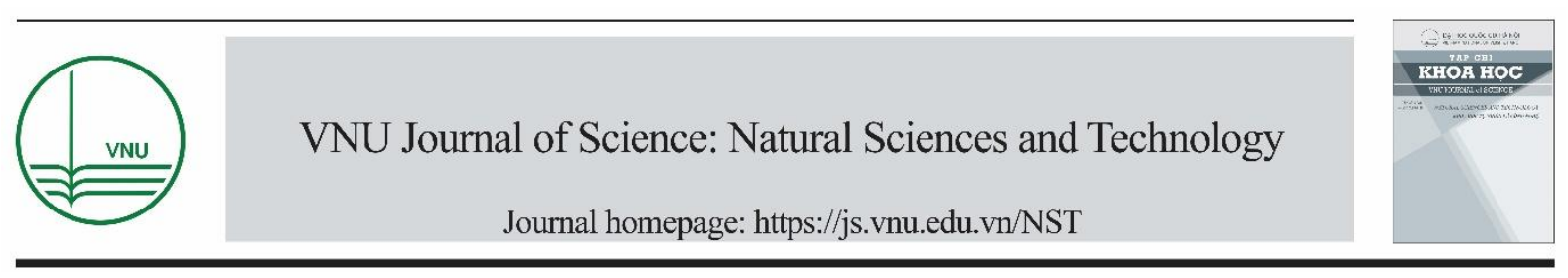

Review Article

\title{
Research and Development of Mobile Marine Satellite Antenna System in Vietnam
}

\author{
Ho Anh Tam, ${ }^{1, *}$, Do Thi Huong Giang ${ }^{1}$, Dang Van Muoi ${ }^{2}$, Nguyen Dinh Van ${ }^{2}$, \\ Nguyen Viet Hung ${ }^{1}$, Nguyen Huu Duc ${ }^{1}$ \\ ${ }^{1}$ Key Laboratory for Micro - Nano Technology, VNU University of Engineering and Technology, \\ E3 Building, 144 Xuan Thuy, Cau Giay, Hanoi, Vietnam \\ ${ }^{2}$ National Center for Technological Progress, Ministry of Science and Technology, C6 Thanh Xuan Bac,
} Hanoi, Vietnam

Received 22 May 2019

Revised 08 June 2019; Accepted 10 June 2019

\begin{abstract}
A second version of the mobile marine satellite communication signal receiver station has been designed, manufactured, assembled and tested using domestically engineered mechanical modules, commercial and low-cost integrated sensors, motors and drivers. The operating mechanical components have been developed in the form of independently operating modules with handling ease and high sensitivity at a "clearance" in the order of $10 \mu \mathrm{m}$. The sensors are of high and firm integration and good noise compensation facilities. The appropriately developed automatic control algorithms and software allow efficient and safe searching and following the broadcasting satellite of the antenna device installed on a marine transport boat. Compared to the previous version, this new development has more optimal dimensions, is easier and more flexible to start up and operate with operating parameters of pitch: $15-80^{\circ}\left( \pm 0.5^{\circ}\right)$, yaw: of $0-360^{\circ}\left( \pm 0.25^{\circ}\right)$, and polarization angle of $0-360^{\circ}\left( \pm 0.5^{\circ}\right)$. The antenna turn rates are of $\sim 12 \%$ and $12^{\circ} / \mathrm{s}^{2}$. All the components of the complete system are water- and weather proof and packaged to ensure safe operation in marine conditions. Running tests have been successfully taken in real sunny weather conditions on a sea boat speeding at $30 \mathrm{~km} / \mathrm{h}$ with a wind velocity up to $19 \mathrm{~km} / \mathrm{h}$. The article concludes that domestically engineered, the device is more financially efficient than imported counterpart equipments as well as promising in terms of technology transfer to mass production by domestic businesses.
\end{abstract}

Keywords: Satellite receiver antenna, marine satellite antenna, antenna angle controller, sensors.

\footnotetext{
${ }^{*}$ Corresponding author.

E-mail address: hoanhtam@vnu.edu.vn
}

https://doi.org/10.25073/2588-1140/vnunst.4903 


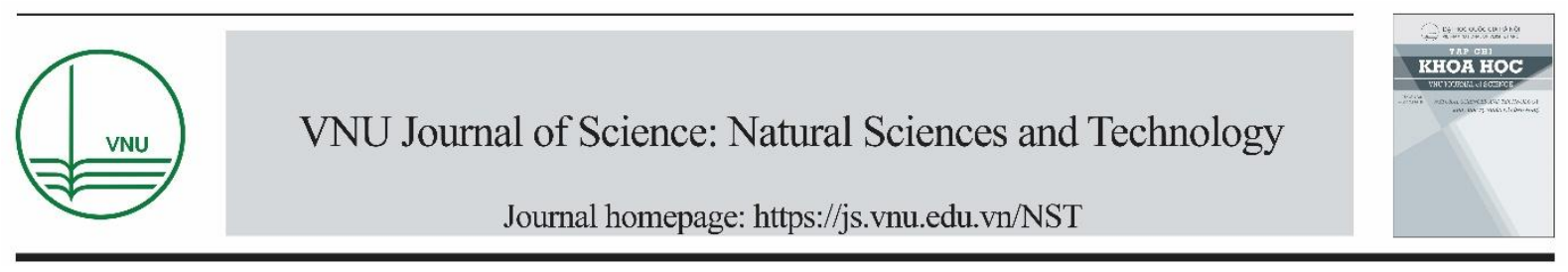

\title{
Nghiên cứu chế tạo trạm thu di động tín hiệu vệ tinh ứng dụng trên tàu biển ở Việt Nam
}

\author{
Hồ Anh Tâm ${ }^{1, *}$, Đỗ Thị Hương Giang ${ }^{1}$, Đặng Văn Mười², Nguyễn Đình Văn², \\ Nguyễn Việt Hùng ${ }^{1}$, Nguyễn Hữu Đức ${ }^{1}$ \\ ${ }^{I}$ PTN trọng điểm Công nghệ Micro-nano, Truòng Đại học Công nghệ, Đại học Quốc gia Hà Nội, \\ 144 Xuân Thủy, Cầu Giấy, Hà Nội, Việt Nam \\ ${ }^{2}$ Viện Úng dụng Công nghệ, Bộ Khoa học và Công nghệ, C6 Thanh Xuân Bắc, Hà Nội, Việt Nam
}

Nhận ngày 22 tháng 5 năm 2019

Chỉnh sửa ngày 08 tháng 6 năm 2019; Chấp nhận đăng ngày 10 tháng 6 năm 2019

\begin{abstract}
Tóm tắt: Hệ thống trạm thu di động thông tin vệ tinh thế hệ thứ hai của Việt Nam đã được nhóm nghiên cứu phát triển thiết kế, chế tạo và lắp ráp hoàn chỉnh hướng tới thương mại hóa sản phẩm đáp ứng nhu cầu trong nước sử dụng các mô-đun cơ khí chế tạo trong nước và các cảm biến tích hợp, mô tơ, driver thương mại giá thành thấp. Các cơ cấu chấp hành được thiết kế và gia công cơ khí với độ chính xác cao $(\sim 10 \mu \mathrm{m})$ thành từng khối độc lập dễ tháo lắp. Các cảm biến có độ nhạy và độ chính xác cao, thời gian đáp ứng nhanh, khả năng bù trừ nhiễu tốt. Các thuật toán và phần mềm điều khiển đã được xây dựng một cách hợp lý và sáng tạo đáp ứng yêu cầu dò tìm và bám vệ tinh của chảo ăng-ten trên tàu biển. So với thế hệ thứ nhất, trạm thu thể hệ mới có kích thước nhỏ gọn, khởi động linh hoạt và dễ sử dụng. Phạm vi hoạt động góc ngẩng: $15-80^{\circ}\left( \pm 0,5^{\circ}\right)$, góc phương vị: $0-360^{\circ}\left( \pm 0,25^{\circ}\right)$, góc phân cực $0-360^{\circ}\left( \pm 0,5^{\circ}\right)$. Ăng-ten đáp ứng với tốc độ quay góc lên tới $12^{\circ} / \mathrm{s}$ và gia tốc góc lên tới $12 \% \mathrm{~s}^{2}$. Toàn bộ hệ thống bao gồm mạch điện tử, linh kiện được đóng gói theo mẫu mã kiểu dáng công nghiệp và đảm bảo an toàn cho hệ thống hoạt động trong điều kiện môi trường biển. Hệ thống đã được kiểm định chạy thử nhiều ngày trên biển khi lắp đặt trên tầu biển chạy với tốc độ nhỏ $30 \mathrm{~km} / \mathrm{h}$ trong điều kiện thời tiết bình thường, gió cấp 3 . Đây là một thiết bị được sản xuất và lắp ráp hoàn toàn trong nước với giá thành chỉ bằng $10-20 \%$ so với thiết bị nhập khẩu được chào bán tại Việt Nam hiện nay, hứa hẹn nhiều tiềm năng khai thác thương mại hóa sản phẩm, hợp tác chuyển giao công nghệ sản xuất cho các cơ sở doanh nghiệp trong nước.
\end{abstract}

Tù khóa: Trạm thu vệ tinh, ăng-ten vệ tinh, ăng-ten tàu biển, cảm biến, điều khiển góc.

\section{Mở đầu}

Hệ thống thông tin vệ tinh hiện nay đã phát triển rất mạnh, phủ sóng nhiều lĩnh vực (internet, tivi, điện thoại, ...). Với nhiều ưu điểm nổi bật như cự ly liên lạc lớn, có khả năng phủ sóng và kết nối ở khắp mọi nơi trên mặt đất, đặc biệt hữu ích cho những nơi mà các công nghệ khác không

\footnotetext{
*Tác giả liên hệ.

Địa chỉ email: hoanhtam@vnu.edu.vn

https://doi.org/10.25073/2588-1140/vnunst.4903
} 
thể thực hiện được như ngoài biển, liên lạc điểm đến đa điểm trên phạm vi rộng cũng như phạm vi toàn cầu, ... nên thông tin vệ tinh đã phát triển nhanh chóng trong 3 thập niên qua. Nước ta có đặc thù địa hình là có bờ biển dài chạy dọc đất nước khoảng 12 nghìn $\mathrm{km}$ với số lượng lớn các tầu đánh bắt cá 130.000 trong đó chỉ có khoảng $10 \%$ được trang bị các phương tiện thông tin liên lạc. Với các phương pháp liên lạc truyền thống như sóng vô tuyến thì có hạn chế là khoảng cách ngắn nên khi các tầu đánh bắt xa bờ khó khăn rất nhiều với việc giữ liên lạc với đất liền để kịp thời có các cảnh báo về thời tiết và đặc biệt trong bối cảnh hiện nay diễn biến phức tạp trên biển Đông. Chính vì vậy việc nghiên cứu và chế tạo thiết bị trạm thu tín hiệu vệ tinh trang bị cho tàu biển là cấp thiết hiện nay. Trong khi các trạm thu vệ tinh cố định đã phát triển khá ổn định (chủ yếu chỉ liên quan đến vấn đề thu, phát và xử lý tín hiệu siêu cao tần), việc thu thông tin vệ tinh trên các trạm di động cần giải quyết nhiều vấn đề phức tạp hơn, nhưng cũng đã được áp dụng rất nhiều ở trên thế giới [1-7].

Với các trạm thu vệ tịnh được gắn trên các phương tiện di động ngoài khơi như tầu, thuyền thì hướng của Ăng-ten so với vệ tinh luôn thay đổi với tốc độ thay đổi phụ thuộc vào tốc độ di chuyển của các phương tiện và phụ thuộc vào điều kiện thời tiết (sóng biển, gió) [5]. Chính vì vậy, bài toán cần phải giải quyết ở đây là trạm thu mặt đất cần có hệ thống điều khiển để định hướng cho Ăng-ten luôn bám đuổi vệ tinh theo thời gian thực bao gồm: (i) cảm biến đo góc độ chính xác cao xác định góc lệch của ăng-ten trong quá trình chuyển động của phương tiện; (ii) cơ cấu điện tử tự động điều khiển nhanh, chính xác, đáp ứng thời gian thực và (iii) cơ cấu cơ khí chấp hành được thiết kế và gia công với độ chính xác cao để ổn định và duy trì định hướng của ăng-ten theo hướng vệ tinh nhằm đảm bảo tín hiệu được duy trì liên tục và thông suốt. Bên cạnh việc phải dò bám vệ tinh do phương tiện mang ăng-ten di chuyển, cần phải quan tâm ứng xử của hệ thống với các thành phần dịch chuyển của tàu. Các nghiên cứu về vấn đề thu thông tin vệ tinh của các trạm di động trên biển đang được nghiên cứu rất có tính thời sự (ví dụ, xem [1,2]). Do đó, việc nghiên cứu, làm chủ công nghệ lõi, sản xuất hệ thống trạm thu thông tin vệ tinh di động thực sự rất cấp bách [7].

Với sự phát triển của công nghệ các mảng ăng-ten mạch dải (microstrip antenna arrays), tín hiệu ăng-ten trên các phương tiện di chuyển với tốc độ đến $350 \mathrm{~km} / \mathrm{h}$ đã có thể xử lý dễ dàng $[8,9]$. Mặc dù giải pháp này có thể đơn giản giản hoá một số khâu về điều khiển, nhưng các ứng dụng phổ biến hiện nay trên tàu thuỷ vẫn chủ yếu sử dụng ăng-ten chảo. Trên thế giới đã có một số hãng thương mại hóa thành công các thiết bị cho phép thu tín hiệu vệ tinh trên tàu biển như các hãng Digisat [10], Paradigm Communication Systems Ltd. [11] and Intelliantech [12].

Ở Việt Nam, trong khuôn khổ Chương trình KH\&CN quốc gia về Công nghệ vũ trụ giai đoạn 2013-2015, Trường ĐH Công nghệ, ĐHQGHN đã triển khai thực hiện đề tài "Thiết kế và chế tạo trạm thu di động thông tin vệ tinh dựa trên sensơ từ trường độ nhạy cao ứng dụng trên tàu biển" [13]. Thế hệ ăng-ten vệ tinh tàu biển thứ nhất ấy đã được thử nghiệm thu được tín hiệu truyền hình $\mathrm{K}+$ trên tàu du lịch tại vùng biển Cát Bà với tốc độ tàu là $30 \mathrm{~km} / \mathrm{h}$ và điều kiện thời tiết bình thường (gió cấp 3 ). Tuy nhiên các nghiên cứu trên sản phẩm này chủ yếu tập trung vào nguyên lý hoạt động, do vậy để hoàn thiện sản phẩm cho mục đích thương mại hóa thì hệ thống cần phải tiếp tục nghiên cứu phát triển cải tiến và hoàn thiện thêm do vẫn còn một số hạn chế cần phải khắc phục như sử dụng chảo ăng-ten bất đối xứng, các mô-tơ, driver cồng kềnh, chưa có phương án bù trôi và sai số cảm biến, đặc biệt nhiễu từ trường do tàu gây ra, chưa tích hợp chế độ tự động dò tìm vệ tinh dựa vào đo cường độ sóng, chưa tích hợp cơ cấu điều khiển góc quay phân cực, thiết kế cơ khí còn chưa tối ưu, thiết bị kồng kềnh khó khăn cho việc vận chuyển và lắp đặt lên tàu biển.

Báo cáo này trình bày tổng quan các giải pháp bao gồm tối ưu cấu hình, linh kiện điện tử tích hợp và các giải pháp thiết kế, gia công và lắp ráp các khối cơ khí; các công nghệ điều khiển áp dụng cho trạm thu thông tin vệ tinh thế hệ thứ hai của Việt Nam do nhóm nghiên cứu thực hiện đề tài cấp ĐHQGHN mã số QG.16.89 phát triển. Thiết bị đã được thử nghiệm thành công, có khả năng phát triển thương mại hóa. 


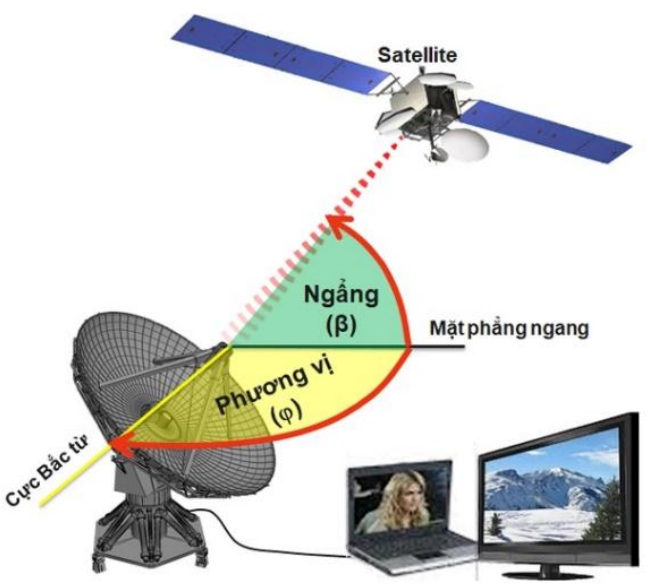

(a)

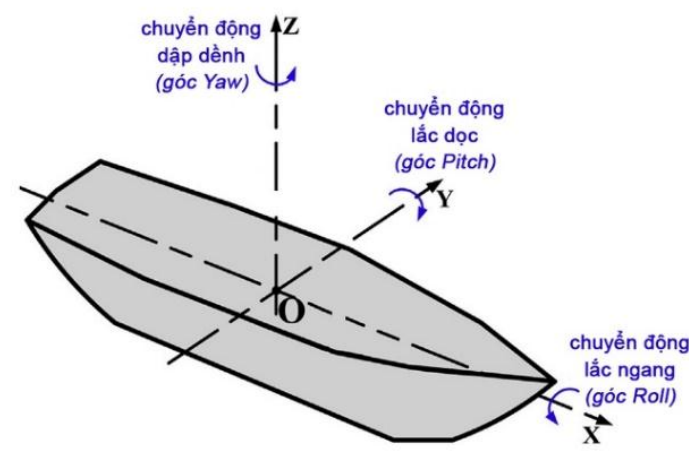

(b)

Hình 1. Sơ đồ xác định vị trí của chảo thu ăng ten vệ tinh (a) [11] và hình minh họa chuyển động của tàu biển (b).

\section{Nguyên lý hoạt động của hệ thống}

Khi trạm thu tín hiệu vệ tinh hoạt động trên biển, bộ phận điều khiển chuyển động sẽ làm nhiệm vụ tiếp nhận tín hiệu đầu vào là thông tin về độ lệch các góc đã qua xử lý đo được từ hệ thống cảm biến bao gồm góc phương vị $\varphi$ (yaw), góc ngẩng $\beta$ (pitch), góc cuộn $\theta$ (roll) và góc phân cực $\alpha$ (polarization) gây ra do chuyển động của tầu (xem hình 1) gửi đến mạch vi điều khiển trung tâm để điều khiển hệ thống truyền động và chấp hành các góc quay của chảo ăng-ten. Sơ đồ nguyên lý hoạt động của hệ thống vi mạch điều khiển động cơ theo tín hiệu đầu vào từ hệ thống cảm biến đo các sai lệch góc phương vị $(\Delta \varphi)$, góc ngẩng $(\Delta \beta)$, góc cuộn $(\Delta \theta)$ và góc phân cực $(\Delta \alpha)$ gẳn trên chảo ăng-ten được được đưa ra trên hình

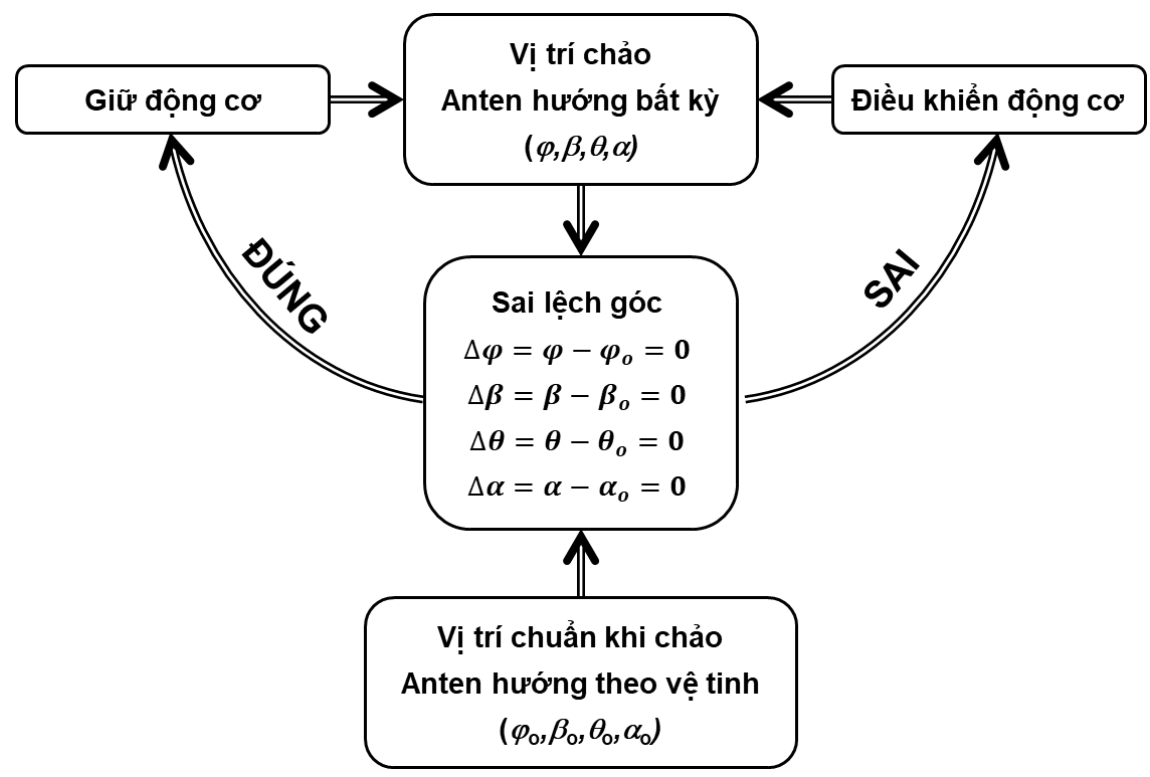

Hình 2. Sơ đồ nguyên lý hoạt động của hệ thống vi mạch điều khiển động cơ theo tín hiệu đầu vào từ hệ thống cảm biến đo góc gắn trên chảo ăng ten [13]. 


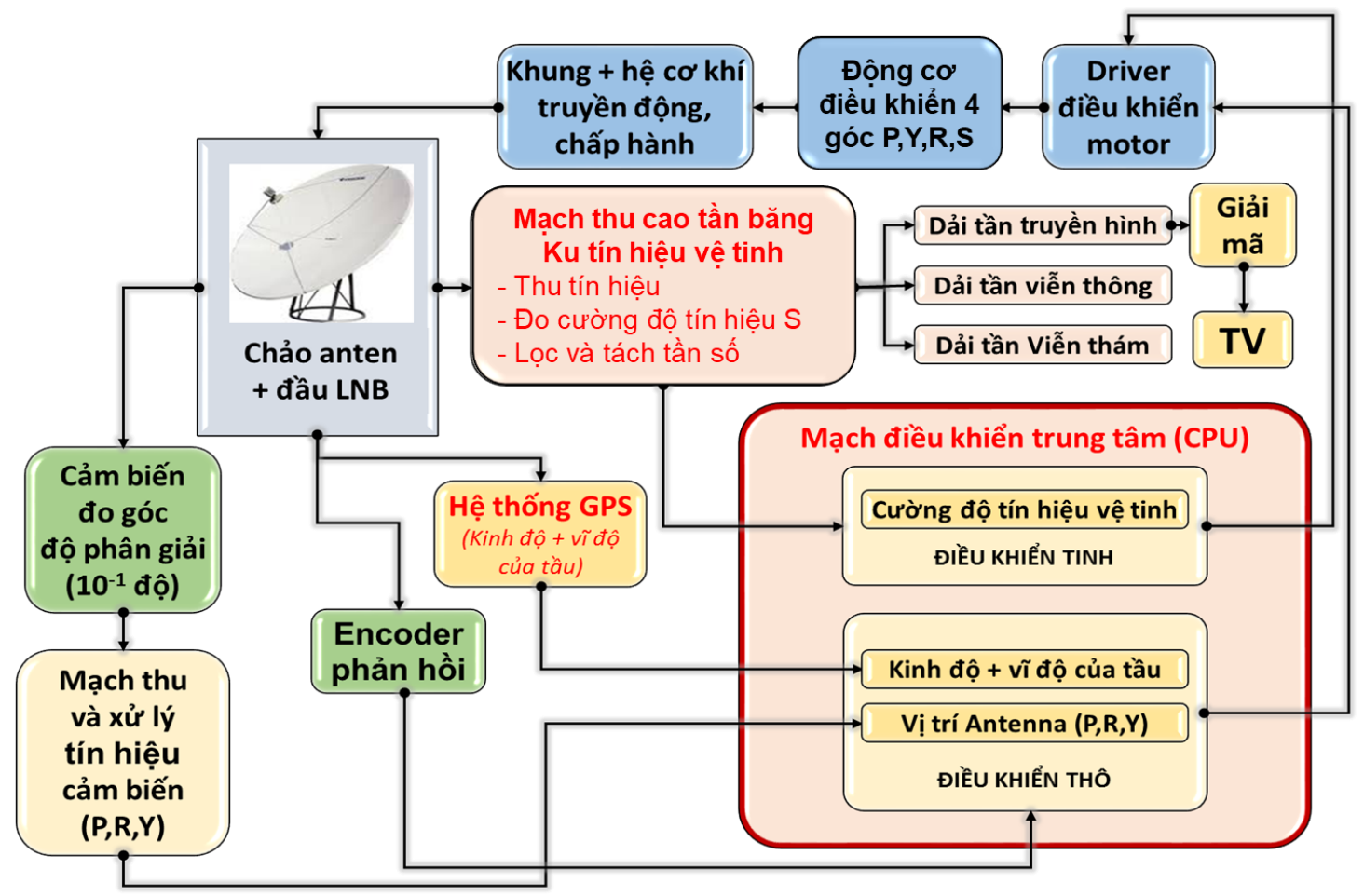

Hình 3. Sơ đồ chức năng hệ thống tự động tìm kiếm và bám sát các góc xác định vị trí chảo ăng-ten bám hướng vệ tinh và góc phân cực được thiết kế cho hệ thống trạm thu thông tin vệ tinh di động $[7,11]$.

Để đảm bảo duy trì thông tin liên lạc được thông suốt thì yêu cầu các cảm biến đo góc và hệ cơ khí truyền động, chấp hành được sử dụng trong hệ thống phải có độ chính xác cao và thời gian đáp ứng nhanh với tốc độ di chuyển theo các trục của phương tiện. Để xác định chính xác góc định hướng của ăng-ten thì bên cạnh các cảm biến đo góc tích hợp bao gồm con quay hồi chuyển, cảm biến đo độ nghiêng, la bàn từ để xác định phương vị Bắc, hệ thống cần sử dụng thêm các Encoder phản hồi đáp ứng được độ phân giải $10^{-1}$ độ để kiểm soát góc quay thực của các cơ cấu điều khiển.

\section{Xác định cấu hình, linh kiện}

Yêu cầu đầu tiên để chế tạo các sản phẩm có thể thương mại hóa được đó là các cấu kiện để chế tạo ra sản phẩm đó phải vừa đảm bảo yếu tố kỹ thuật, vừa phải đảm bảo yếu tố về giá thành.
Dưới đây là một số kết quả cập nhật của đề tài nghiên cứu.

\subsection{Chảo ăng-ten và kim thu LNB}

Hiện tại các hãng khai thác truyền hình vệ tinh tại Việt Nam sử dụng băng tần $\mathrm{Ku}$ (12$18 \mathrm{GHz}$ ) thông qua vệ tinh VINASAT 2. Việc thu truyền hình vệ tinh được thực hiện thông qua việc sử dụng một chảo ăng-tendạng parabol để hội tụ tín hiệu vào bộ kim thu LNB (Low-NoiseBlock downconverter) (hình 4). Tín hiệu sau khi được xử lý tại LNB sẽ được chuyển tới đầu thu giải mã (Receiver) bằng cáp đồng trục $75 \Omega$. Đó là các chảo bất đối xứng. Ưu điểm của loại chảo này là lòng chảo nông, đồng nghĩa với tiêu cự hội tụ dài, nên việc hội tụ tín hiệu vào LNB là khá dễ dàng, thậm chí nhiều LNB có thể tích hợp vào để sử dụng trên cùng một chảo, giúp cho việc lắp đặt tại các hộ dân thuận lợi hơn. Tuy nhiên, với loại chảo này do không có ống dẫn sóng nên vị 
trí đặt đầu thu LNB tại tiêu điểm của chảo và vị trí này khá xa mặt chảo, nên hầu hết loại chảo này chỉ phù hợp với việc lắp đặt cố định. Trong trường hợp trạm thu di động, bán kính quét của hệ chảo này là rất lớn, khiến cho thiết bị trở nên cồng kềnh, phát sinh rất nhiều về chi phí cũng như khó khăn trong lắp đặt vận hành cũng như gia tăng mô-men cho các cơ cấu điều khiển và các động cơ. Mặt khác, do tiêu cự dài nên cường độ tín hiệu thu được tại vị trí đặt LNB của loại chảo bất đối xứng này là không cao. Khi tín hiệu bị suy hao do yếu tố thời tiết (mây dày hoặc mưa lớn) thì cường độ tín hiệu không đủ để duy trì sự ổn định liên tục. Các nhược điểm nêu trên đã được khắc phục bằng việc sử dụng chảo ăng-ten đối xứng có tiêu điểm nằm gần mặt chảo cùng với sự kết hợp ống dẫn sóng giúp cho việc bố trí đầu thu LNB chỉ cần nằm trên trục của ống dẫn sóng và nhờ đó thu gọn kích thước hệ thống, đồng thời nâng cao cường độ tín hiệu thu được (Hình 4a).
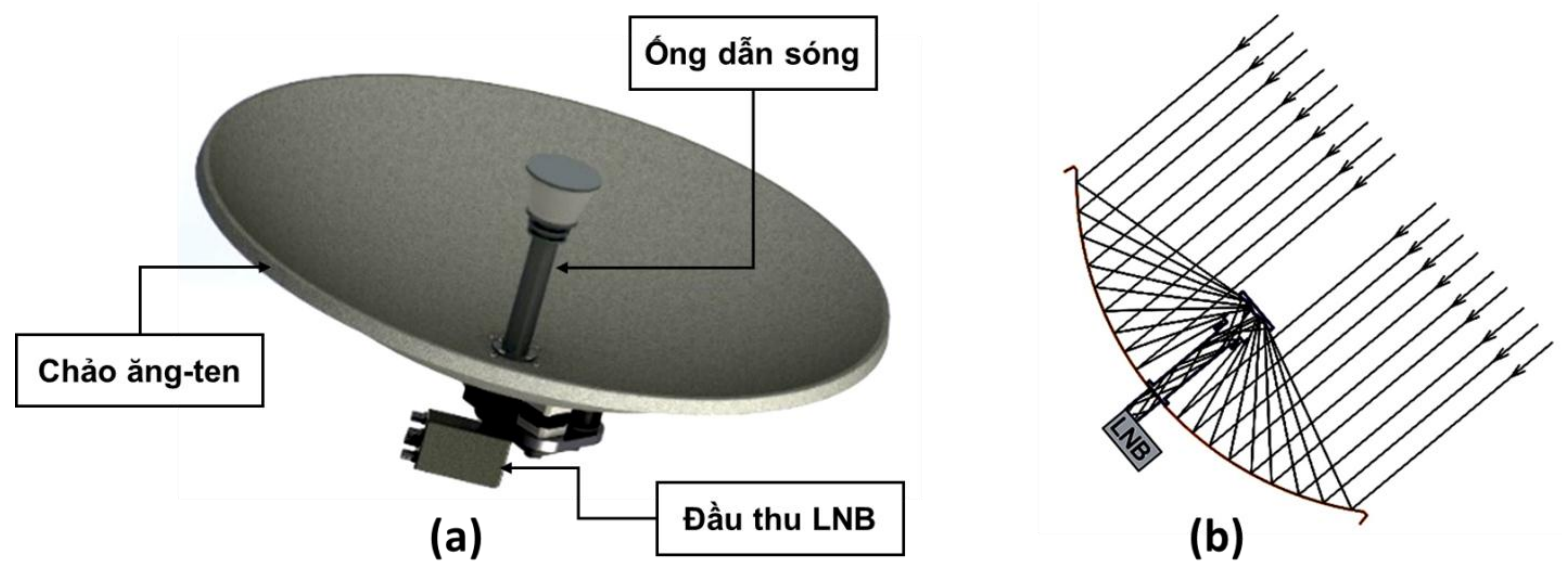

Hình 4. Chảo ăng-ten đối xứng (a) và nguyên lý dẫn sóng tín hiệu thu từ vệ tinh vào đầu thu LNB (b).

Trong mẫu thiết kế, chảo parabol được có đường kính $61 \mathrm{~cm}$, với hai mặt phản xạ tín hiệu. Khi quay chảo về đúng hướng vệ tinh, tín hiệu được phản xạ lần đầu trên mặt chảo và hội tụ tại tiêu điểm của chảo. Tại đây, tín hiệu được phản xạlần thứ 2 để đi vào ống dẫn sóng và gặp đầu thu LNB được bố trí ở sau mặt chảo nằm trên trục của ống dẫn (Hình 4b). Với cách bố trí này, ngoài các ưu điểm như thu gọn kích thước của hệ thống và tăng cường cường độ sóng, độ hội tụ tín hiệu, việc bố trí cơ cấu quay góc phân cực (tức là quay kim thu LNB) cũng được thực hiện dễ dàng hơn.

LNB dùng cho dải tần $\mathrm{Ku}$ có rất nhiều loại nhu: single $\mathrm{LNB}$, twin $\mathrm{LNB}$, dual $\mathrm{LNB}$ và universal LNB... Trong đó universal LNB được sử dụng phổ biến nhất. LNB này gồm có 2 tần số dao động nội hoạt động một cách độc lập với nhau với hai dải tần đầu vào, một dải tần số thấp $(10.7-11.7 \mathrm{GHz})$ và một dải tần số cao $(11.7$ $12.75 \mathrm{GHz})$. Như vậy LNB này cũng sẽ có 2 dải trung tần khác nhau ở đầu ra $(950-1950 \mathrm{MHz}$ và $1100-2150 \mathrm{MHz}$ ), cho phép 2 đầu thu giải mã chạy độc lập trên hai phân cực riêng biệt. Universal LNB cũng bao gồm twin LNB, quad $\mathrm{LNB}$, octo LNB... tương ứng với $2,4,8 \ldots$ ngõ lối ra của tín hiệu độc lập để có thể sử dụng cáp đồng trục đưa tới $2,4,8 \ldots$ dầu thu giải mã. Trong nghiên cứu này, chúng tôi lựa chọn loại universal quad LNB với 4 ngõ ra tín hiệu độc lập (Mã số K044, của hãng Infosat, Thái Lan). LNB này cho phép sử dụng nhiều đầu thu mà không cần sử dụng tới các bộ chia tín hiệu. Hơn thế nữa, nó còn cho phép sử dụng một trong số các đầu ra tín hiệu để dùng cho mục đích điều khiển. 


\section{2. Động cơ và bộ điều khiển (driver)}

Trong các nghiên cứu trước đây, động cơ và bộ điều khiển servo được sử dụng với các ưu điểm nổi bật là mômen trên trục đều, tốc độ cao, mạch điều khiển tốc độ chính xác, làm việc êm... Tuy nhiên, đối với mục đích thương mại hóa, loại động cơ này có những nhược điểm như chi phí lớn, không làm việc ở chế độ mạch điểu khiển hở, yêu cầu phải có hệ thống phản hồi, yêu cầu phải điều chỉnh các thông số vòng điều khiển và bảo dương tốn kém, động cơ và driver servo phải tương thích với nhau, đồng nghĩa với việc khi thay thế thì phải thay đồng bộ, rất tốn kém...

Giải pháp thay thế cho động cơ servo có thể là động cơ một chiều hoặc mô-tơ bước. Tuy nhiên nhược điểm của động cơ một chiều là mômen nhỏ, để tăng momen phải thêm các tầng bánh răng (hộp số) làm tăng kích thước của động cơ. Trong các trạm thu truyền hình vệ tinh di động ngoại nhập, các mô-tơ cơ bước thường được sử dụng. Trong quá trình thực hiện nghiên cứu, động cơ bước và động cơ một chiều đã được thử nghiệm. Nhận thấy rằng động cơ bước có nhiều ưu thế đáng kể về giá thành rẻ, có thể điều khiển mạch hở (không cần có tín hiệu phản hồi), duy trì mô-men rất tốt (không cần phanh, biến tốc), mô-men xoắn cao ở tốc độ thấp (đặc biệt phù hợp cho chuyển động của trục phương vị có tải nặng và không cần tốc độ cao). Hơn thế nữa, chi phí bảo dưỡng cũng thấp (không có chổi than), định vị chính xác, không phải điều chỉnh các thông số điều khiển.

Driver của động cơ bước được sản xuất cho mục đích công nghiệp cũng cho phép điều chỉnh các thông số quan trọng như dòng điện (tương ứng là mô-men của động cơ), số xung (tương ứng với độ mịn điều khiển). Nhờ đó, có thể lựa chọn cùng một loại động cơ và driver cho tất cả các trục chấp hành của hệ. Mặt khác, mọi động cơ bước và driver đều tương thích với nhau. Điều này có thuận lợi trong việc bảo trì, chỉ cần dự phòng một động cơ và driver cho tất cả các trục.

Trong nghiên cứu này, chúng tôi sử dụng động cơ Sumtor 57HS5630A4 1.2Nm và driver điều khiển Leadshine DM542-05 cho các trục quay phương vị, trục ngẩng và trục nghiêng; động cơ CB609-3527 6V 0.9 và driver điều khiển M6600-4Acho trục quay LNB. Các driver đều áp dụng phương pháp hiện đại nhất hiện nay trong điều khiển động cơ bước là phương pháp vi bước (microstep), thường là phương pháp vi bước sin cosin. Trong phương pháp này, dòng điện qua cuộn dây có dạng sóng xấp xỉ với hàm sin. Khi càng chia nhiều vi bước, dạng sóng càng gần với dạng sin, giúp giảm đáng kể rung động của động cơ. Phân giải theo lý thuyết sẽ tăng lên theo số chia vi bước. Tuy nhiên, trong thực tế thiết kế cơ khí của động cơ quyết định số bước chia tối đa mà động cơ có thể dịch chuyển trong sai số cho phép. Độ phân giải của các driver này có thể lên đến $1 / 32$ step giúp điều khiển động cơ hoạt động chính xác. Những mạch điều khiển này được thiết kế với vỏ bằng kim loại chống nhiễu, chắc chắn, có cơ cấu tản nhiệt giúp hoạt động trong thời gian dài và ổn định. Độ phân giải lớn cùng với khả năng lập trình điều khiển dễ dàng là những điều quan trọng nhằm điều khiển cho động cơ bước hoạt động ổn định và hiệu quả.

\subsection{Mạch điều khiển trung tâm}

Xu hướng được cộng đồng khởi nghiệp sử dụng rộng rãi hiện nay là phát triển các sản phẩm sử dụng các mã nguồn mở và công cụ với đông đảo người dùng. Điều này giúp tiết kiệm chi phí nghiên cứu, dễ dàng tìm được giải pháp hỗ trợ khi gặp vướng mắc. Hầu hết các vấn đề công nghệ trong thực tế đều đã có các nhóm phát triển chuyên biệt, do vậy các nhà nghiên cứu không chuyên về một lĩnh vực nào đó đều có thể tìm được các giải pháp đã được chia sẻ công khai với sự góp ý của cộng đồng người dùng phong phú. Theo xu thế đó, nghiên cứu này cũng tiếp cận và tham khảo các kết quả liên quan trong cộng đồng Arduino.

Các mạch điều khiển arduino không chỉ có cộng đồng phát triển đông đảo, mà còn có các KIT mở rộng chuyên dùng cho các mục đích khác nhau rất phong phú. Cấu hình của mạch 
điều khiển trung tâm arduino cũng có những sự lựa chọn với thông số kỹ thuật đủ cao để thực hiện các tác vụ phức tạp, chứ không đơn thuần chỉ phục vụ các công việc mang tính chất thử nghiệm hay nghiên cứu đơn giản (hình 5). Trong đó, MEGA2560 ATMEGA16U2 là một bộ điều khiển đủ mạnh đóng vai trò là CPU thực hiện nhiệm vụ tính toán điều khiển. Các thông số kỹ thuật chính bao gồm:

- Vi điểu khiển Atmega2560.

- Điện áp hoạt động 5 VDC.

- Điện áp ngõ vào DC 7-12 VDC.

- Số chân Digital 54 (15 chân PWM)

- Số chân Analog 16.

- Bộ nhớ Flash 256 kB, 8 kB sử dụng cho Bootloader.

- SRAM 8 kB.

- EEPROM $4 \mathrm{kB}$.

- Xung clock $16 \mathrm{MHz}$.

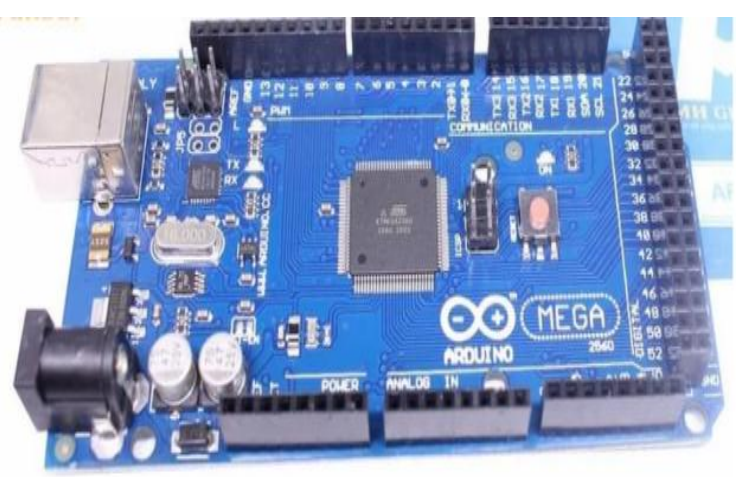

Hình 5. KIT Arduino MEGA2560 ATMEGA16U2.

\subsection{Cảm biến đo vị trí góc}

Để ghi nhận đầy đủ chuyển động của tàu biển và bù lại trong quá trình điều khiển, cần sử dụng tới các cảm biến sau: cảm biến từ trường 3 trục (3D magnetometer) đóng vai trò như một la bàn để đo góc phương vị; cảm biến gia tốc 3 trục (3D Accelerometer) và cảm biến đo tốc độ quay quanh trục đối với cả 3 trục không gian (3D
Gyroscope) được kết hợp để đo 2 góc còn lại là góc ngẩng và góc nghiêng của hệ thống. Riêng với góc phân cực thì vị trí góc được đo và điều khiển sử dụng encoder tích hợp vào hệ thống trục quay góc phân cực.

Với sự phát triển của công nghệ vi chế tạo, các vi mạch chứa các cảm biến được tích hợp sẵn, cùng với các thuật toán đã được các nhà sản xuất phát triển, cho phép người dùng khai thác dữ liệu từ các cảm biến một cách chính xác dưới dạng các thông tin điện áp hoặc dòng điện đơn giản. Trong đó, cảm biến gia tốc và tốc độ quay đã được kết hợp để tạo thành mô-đun IMU (Inertial Measurement Unit) với 6 trục tự do 6DOF (DegreesOf Freedom). Nhóm nghiên cứu đã tiến hành đo kiểm chứng rất nhiều các loại vi mạch, với mục tiêu chọn ra vi mạch cảm biến có tín hiệu đáng tin cậy nhất trong khoảng chi phí chấp nhận được và lựa chọn cảm biến JY901 của WIT Motion. JY901 không chỉ được tích hợp đầy đủ các loại cảm biến kể trên, mà còn được tích hợp sẵn bộ lọc Kalman để tính toán và xử lý trong thời gian thực. Các bộ lọc hoạt động hiệu quả để khử nhiễu và nâng cao độ chính xác của phép đo. Độ chính xác góc lên tới $0.05^{\circ}$. Encoder đo góc quay phân cực được sử dụng là Encoder quang học GTA3806-400 tương đối với 400 xung/1 vòng.

\subsection{Khối đo cuờng độ sóng}

Khối cảm biến đo cường độ tín hiệu được sử dụng trong hệ thống với chức năng đo cường độ tín hiệu vệ tinh, giúp cho chảo ăng-ten dò tìm được chính xác vị trí của vệ tinh trong trường hợp việc bám hướng của chảo có sai số gây ra do sai số của hệ thống các cảm biến đo góc được tích hợp vào chảo. Qua các nghiên cứu, khối thu cường độ sóng được tích hợp trong hệ thống này dựa trên sản phẩm thương mại của các bộ dò vệ tinh (satellite finder) SATLINK WS-6903, vốn được sử dụng rất hiệu quả và phù hợp cho việc hiệu chỉnh xác định hướng các chảo thu vệ tinh khi lắp đặt cố định trên mặt đất. 
3.6. So đồ nguyên lý

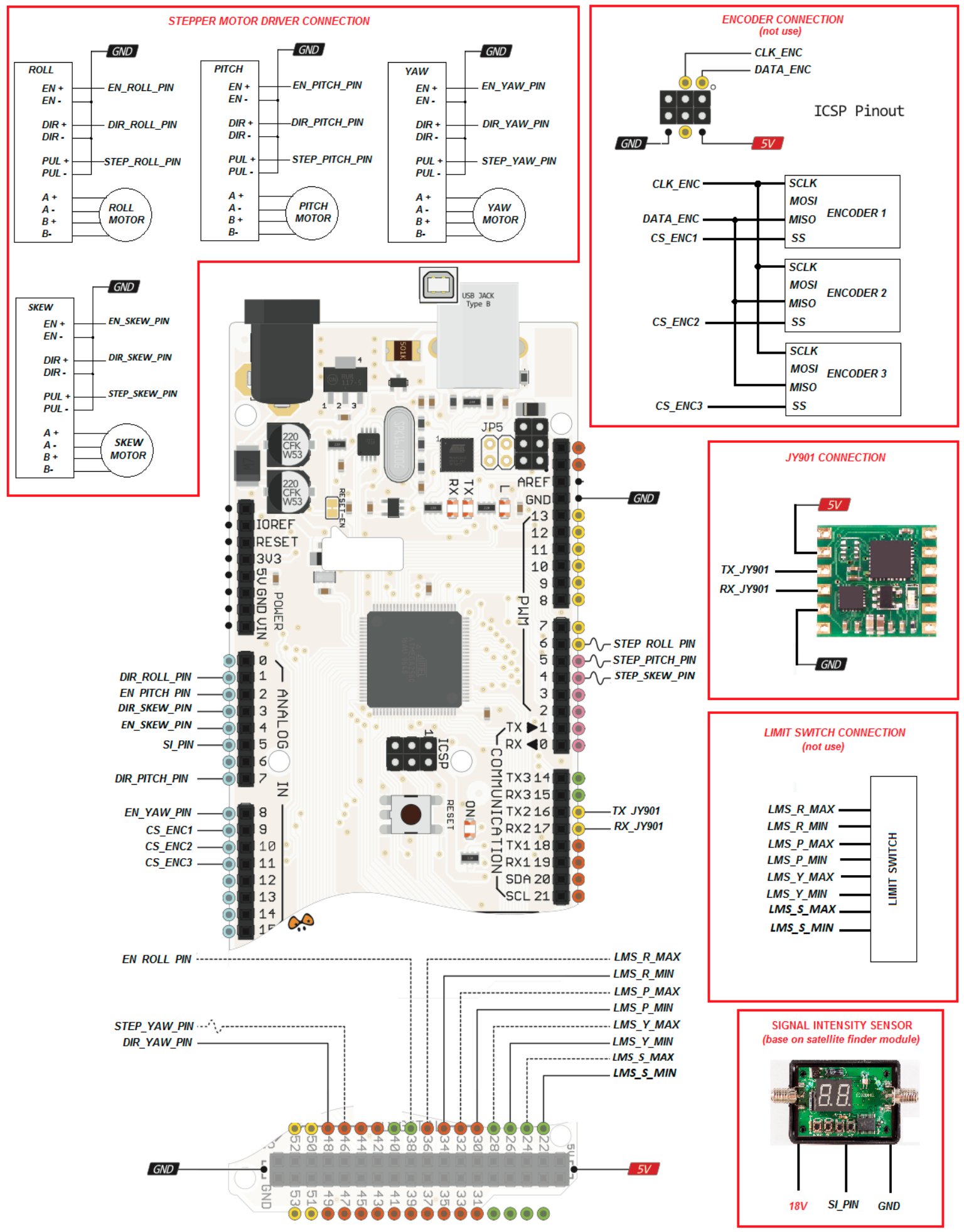

Hình 6. Sơ đồ nguyên lý hệ thống. 


\section{Thiết kế và gia công cơ khí}

Một đặc tính quan trọng cần phải có trong thiết kế cơ khí đó là phải đảm bảo yêu cầu về tính mô-đun hóa, tức là tính độc lập tương đối giữa các trục với nhau. Điều này tạo ra độ linh hoạt và tính chuyên môn hóa trong quá trình chế tạo và lắp đặt, đồng thời giúp cho quá trình bảo trì, sữa chữa dễ dàng hơn vì có thể duy trì hoạt động của các trục độc lập. Thay vì hệ thống 3 trục quay được phát triển của các nghiên cứu trước, nghiên cứu này đã cải tiến tăng bậc tự do của hệ thống lên 4 bậc tương ứng với 4 trục quay góc điều khiển quay (phương vị, ngẩng, nghiêng (cuộn) và góc phân cực). Với việc nâng số bậc tự do của hệ thống này giúp hệ thống đáp ứng nhanh hơn và mịn hơn với chuyển động của tàu, có thể sử dụng được với các loại tầu khác nhau, đặc biệt với tàu loại nhỏ mà hệ thống 3 trục không thể đáp ứng được.

Thiết kế tổng thể của trạm thu tín hiệu vệ tinh với các mô-đun cơ khí độc lập được trình bày trên hình 7. Các chi tiết cấu thành thiết bị được gia công hoàn thiện từ các vật liệu dạng tấm (nhựa acrylic) và dạng thanh (nhôm định hình) bằng các phương pháp cắt đơn giản. Do vậy chi phí gia công được tiết kiệm tối đa mà vẫn đảm bảo tính năng của các chi tiết. Đây đều là các vật liệu không từ tính để đảm bảo không gây tác động nhiễu từ lên hệ thống cảm biến nhưng đồng thời cũng là các vật liệu không oxy hóa phù hợp với điều kiện làm việc ở ngoài biển.

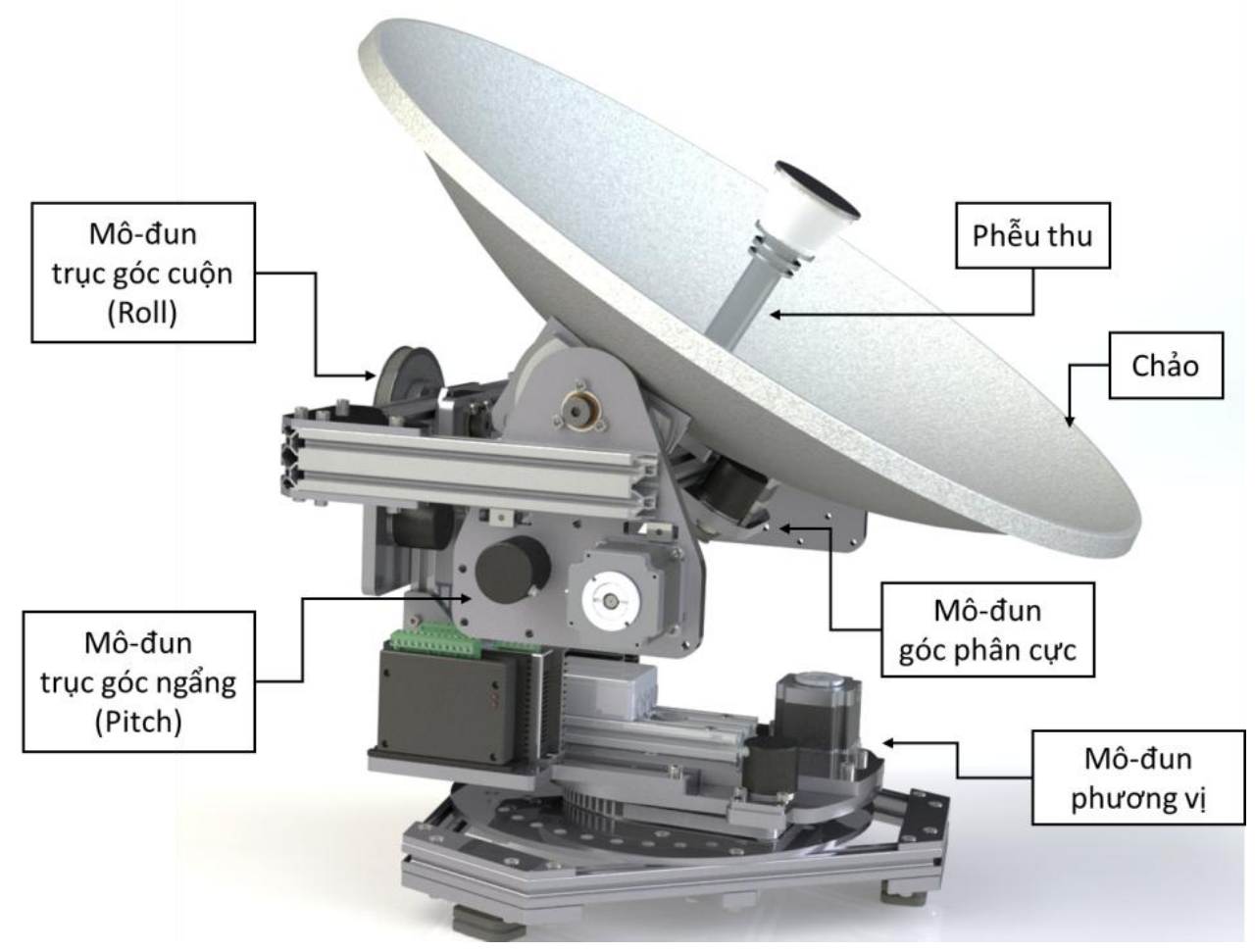

Hình 7. Thiết kế tổng thể của trạm thu với các mô-đun cơ khí độc lập.

\subsection{Mô-đun LNB}

Cơ cấu điều hướng kim thu LNB (Skew Polarization) cho phép điều khiển đầu thu của chảo ăng-ten để thu được tín hiệu từ vệ tinh với cường độ cực đại. Sóng điện từ từ VINASAT2 là sóng phân cực, với góc phân cực tại Hà Nội là $\alpha_{o}=-48,9^{\circ}$. Do vậy cần luôn duy trì trạng thái 
của kim thu bám theo góc phân cực này để đạt tín hiệu cực đại. Góc phân cực này thay đổi tùy theo loại vệ tinh và vị trí lắp đặt chảo ăng-ten.

Như đã phân tích ở trên, cơ cấu hội tụ tín hiệu của chảo parabol đối xứng cho phép đặt LNB phía sau mặt chảo, thuận lợi cho việc bố trí các cơ cấu chấp hành mà không che chắn làm suy hao tín hiệu thu được. Đặc điểm của quay trục LNB là mô-men nhỏ, tốc độ đáp ứng không cần quá lớn đối với ứng dụng thu truyền hình vệ tinh. Qua khảo sát thực nghiệm được thực hiện bởi nhóm nghiên cứu, khi quay đầu thu để tạo ra độ lệch góc phân cực $\Delta \alpha=\alpha-\alpha_{o}$ khác nhau, kết quả đo cường độ tín hiệu trên Hình 8 cho thấy trong dải độ lệch $\Delta \alpha$ từ $-40^{\circ}$ đến $40^{\circ}$, tín hiệu truyền hình vệ tinh thu được luôn ở mức $100 \%$ (trên ngưỡng xem được trên màn hình TV). Điều này có nghĩa là sai số cho phép điều khiển đối với trục LNB là khá rộng. Tuy nhiên, việc quay góc phân cực sẽ có ý nghĩa rất lớn để sản phẩm trạm thu có thể sử dụng trên phạm vi toàn cầu. Chỉ cần xây dựng cơ sở dữ liệu của hệ thống vệ tinh địa tĩnh toàn cầu, người dùng hoàn toàn có thể lựa chọn vệ tinh phù hợp trên địa bàn mà tàu biển di chuyển, từ đó trạm thu sẽ tự động điều chỉnh góc quay kim thu LNB tới vị trí phù hợp với vệ tinh được chọn.

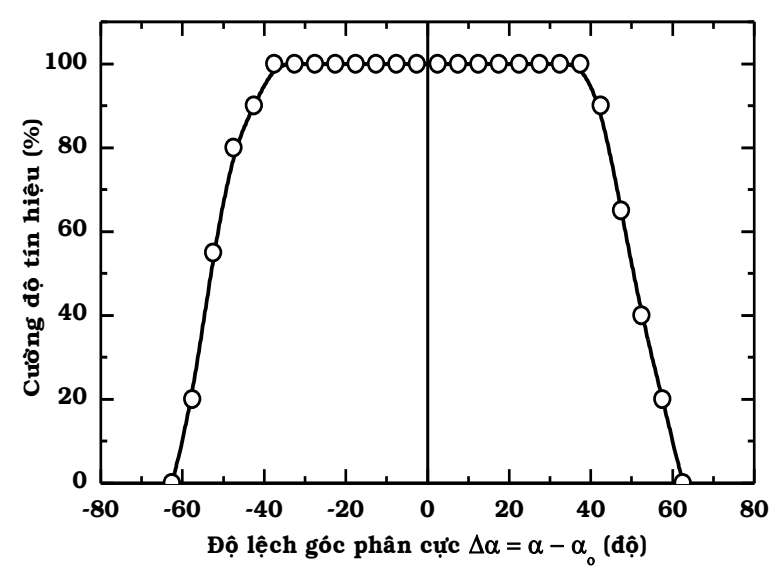

Hình 8. Sự ổn định tín hiệu phụ thuộc góc quay kim thu LNB.

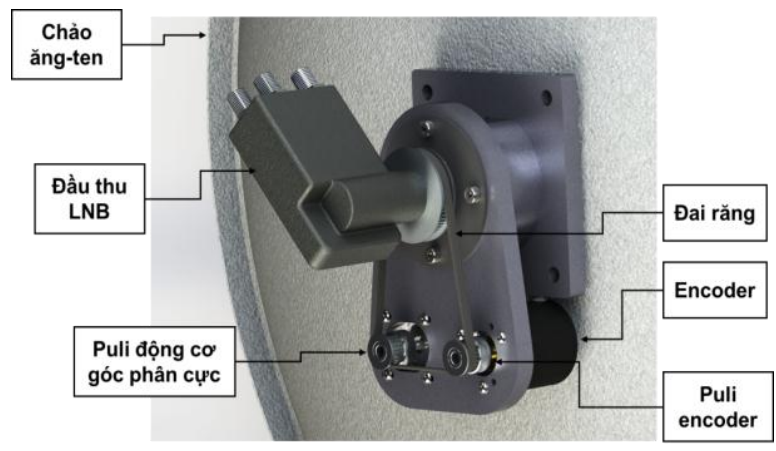

Hình 9. Cơ cấu của mô-đun LNB trong trạm thu tín hiệu vệ tinh.

Trục LNB cũng được thiết kế cơ cấu để gắn kết với chảo parabol và ống dẫn sóng, tạo thành một khối độc lập. Do mô-men quay của trục LNB là không lớn, nên đối với trục LNB, trong cơ cấu truyền chỉ cần sử dụng cơ cấu truyền động dây đai (puli) với cơ cấu điều chỉnh độ căng dây đai bằng việc dịch chuyển puli của động cơ trục LNB (hình 9). Hệ dây đai được sử dụng là MXL rộng $5 \mathrm{~mm}$, tỉ lệ truyền là $1 / 3$. Với tỉ lệ truyền này, độ chính xác góc phân cực đo bởi encoder được xác định là $0,3^{\circ}$.

\subsection{Mô-đun trục ngẩng}

Mô-đun trục ngẩng đóng vai trò thay đổi góc ngẩng của chảo hướng tới vệ tinh, đồng thời đóng vai trò liên kết giữa trục LNB và trục quay nghiêng. Trục LNB cùng với chảo parabol được gắn vào giữa khung nhôm định hình liên kết hai mặt bích của trục ngẩng (Hình 10). Một mặt bích gồm các cơ cấu dẫn động theo nguyên lý dây đai với dạng đai là MXL bản $10 \mathrm{~mm}$, tỉ số truyền là $1 / 8$, cơ cấu căng đai là 2 puli trơn có trục gắn ổ bi. Với tỉ số truyền này, độ chính xác góc phản hồi góc quay được đo đạc bởi các encoder được đánh giá cỡ 0,1 độ. Giá trị này đáp ứng yêu cầu về thông số kỹ thuật theo yêu cầu đặt ra của hệ thống. Điểm đặc biệt ở trục này là puli gắn với trục quay góc ngẩng được vát ở mặt tiếp giáp với phía sau mặt chảo. Mặt vát này giúp tối ưu không gian gắn chảo ăng-ten mà vẫn đảm bảo dải quay góc ngẩng của chảo ăng-ten. 


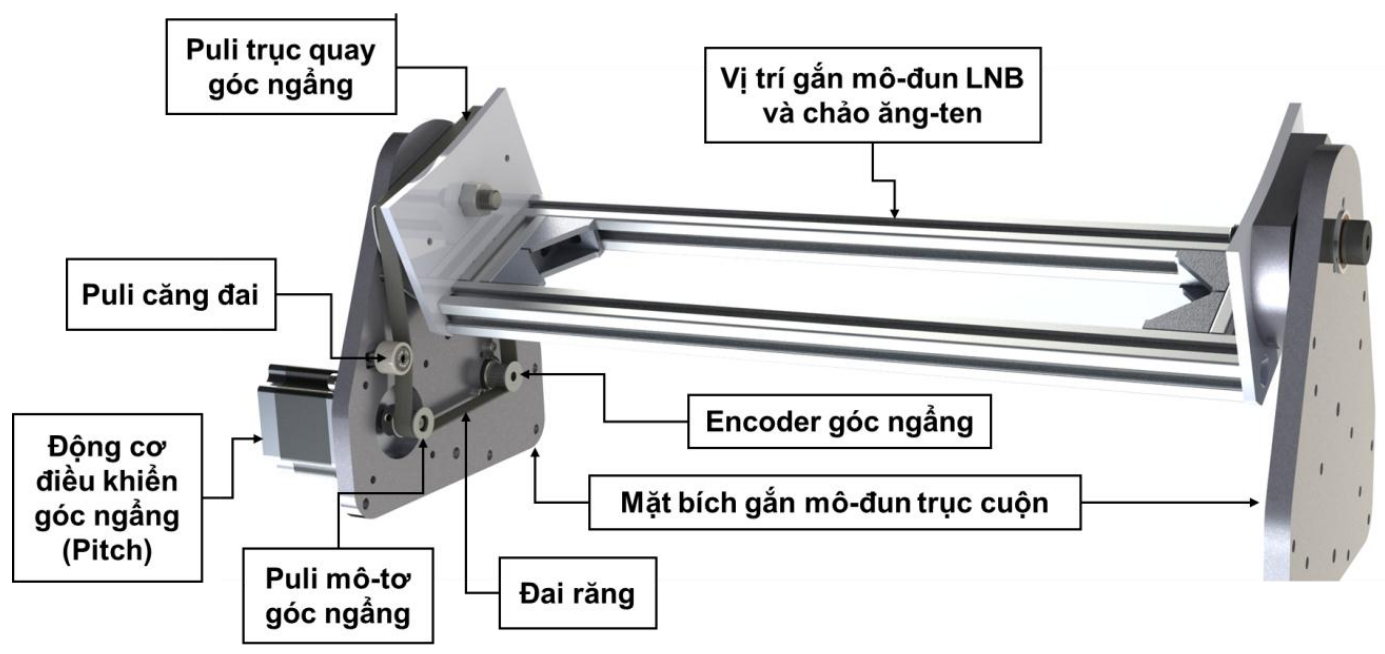

Hình 10. Cơ cấu của mô-đun trục ngẩng.

Với vai trò liên kết của mình, trục ngẩng vẫn sử dụng cơ cấu truyền động trên cùng một mặt bích, do vậy đảm bảo được tính ổn định của trục trong quá trình hoạt động, đồng thời cho phép việc thay thế bảo dưỡng dễ dàng và độc lập.

\subsection{Mô-đun trục cuộn}

Trục góc nghiêng/cuộn không chỉ thực hiện vai trò điều khiển góc quay nghiêng (Roll) mà còn liên kết trục ngẩng và trục phương vị. Trục ngẩng được gắn lên khung chữ U chế tạo bởi các thanh nhôm định hình, đồng thời liên kết với trục phương vị thông qua một bệ đỡ dạng chữ L. Trong trường hợp này, cơ cấu trục cuộn có điểm đặc biệt là cho phép điều chỉnh được chiều cao của khung chữ $U$, sao cho trọng tâm của hệ là thấp nhất mà vẫn đảm bảo góc ngẩng dao động trong biên độ cần thiết. Cơ cấu truyền, các thông số và cơ cấu truyền động của trục cuộn tương tự trục ngẩng được đưa ra trên Hình 11.

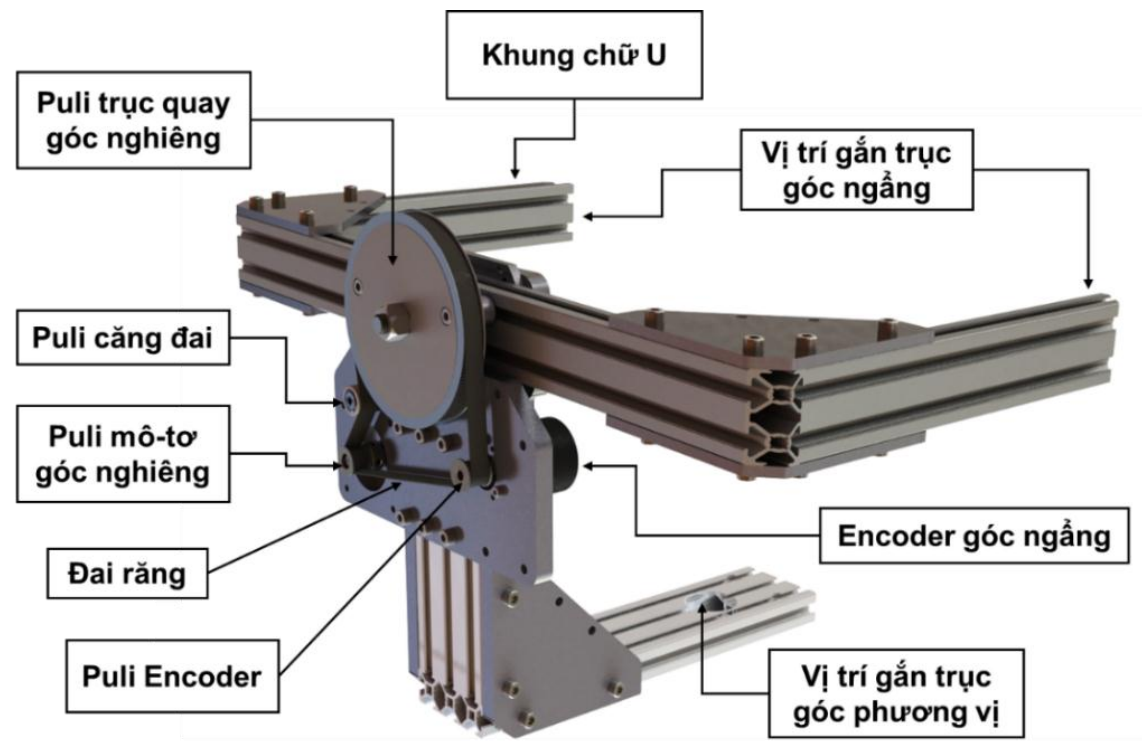

Hình 11. Cơ cấu của mô-đun trục góc nghiêng/cuộn. 


\subsection{Mô-đun truc phuoong vị}

Trục phương vị là trục chuyển động có mômen lớn nhất do phải chịu tải trọng của toàn bộ các cơ cấu kể trên. Tuy nhiên do vận tốc chuyển động quay của tàu trong mặt phẳng là không quá lớn, nên động cơ bước trong trường hợp này vẫn đảm bảo phù hợp để thực hiện tốt chức năng của mô-đun này.

Trong đề tài nghiên cứu trước đây, một vòng bi côn đã được sử dụng để đảm bảo chịu tải và quay đồng tâm cho trục phương vị. Tuy nhiên, vòng bi côn chỉ đảm bảo chịu tải theo phương thẳng đứng, mà không tạo ra liên kết giữa các mô-đun bên trên với đế bên dưới. Nói một cách khác, khi tàu dao động tới một góc nghiêng nhất định khiến khối tâm của hệ rơi khỏi mặt chân đế, thì toàn bộ các mô-đun bên trên sẽ bị đổ. Để khắc phục vấn đề này, một vòng bi lăn chéo (crossed roller bearings) đã được sử dụng cho trục phương vị (Hình 12). Vòng bi này có đầy đủ tính chất của vòng bi côn, ngoài ra còn tạo ra một mặt chân đế rộng hơn, tạo liên kết giữa chân đế và các mô-đun phía trên, đồng thời lỗ thoát giữa vòng bi lớn hơn giúp tránh hiện tượng xoắn búi dây khi hệ quay trong mặt phẳng chân đế.

Mô-đun trục quay góc phương vị có một mặt bích để gắn với trục nghiêng tại mặt nhôm định hình chữ $\mathrm{L}$ với các vị trí được định sẵn. Hệ truyền động của trục quay góc này được liên kết với mặt chân đế dạng tam giác với các chân cao su (chân chống rung) có chức năng triệt tiêu các dao động có tần số cao tác động lên hệ như động cơ của tàu, máy nổ... Để đảm bảo chịu được mômen lớn, trục phương vị sử dụng cơ cấu truyền động dây đai hệ $3 \mathrm{M}$, tỉ số truyền $1 / 8$ (Hình 13).
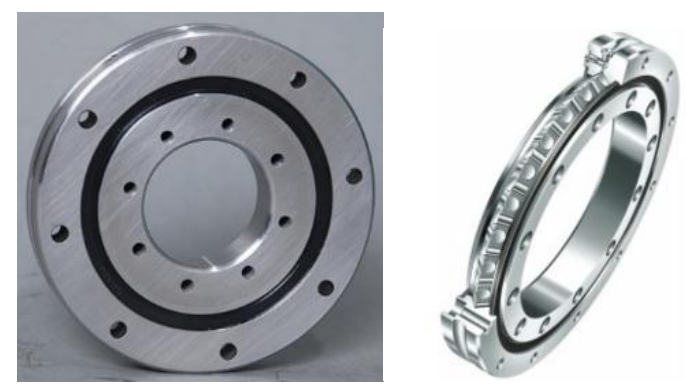

Hình 12. Cấu trúc tổng thể và cấu trúc bên trong vòng bi lăn chéo RU85UUCCO, của hãng Crown Pro, Trung Quốc.

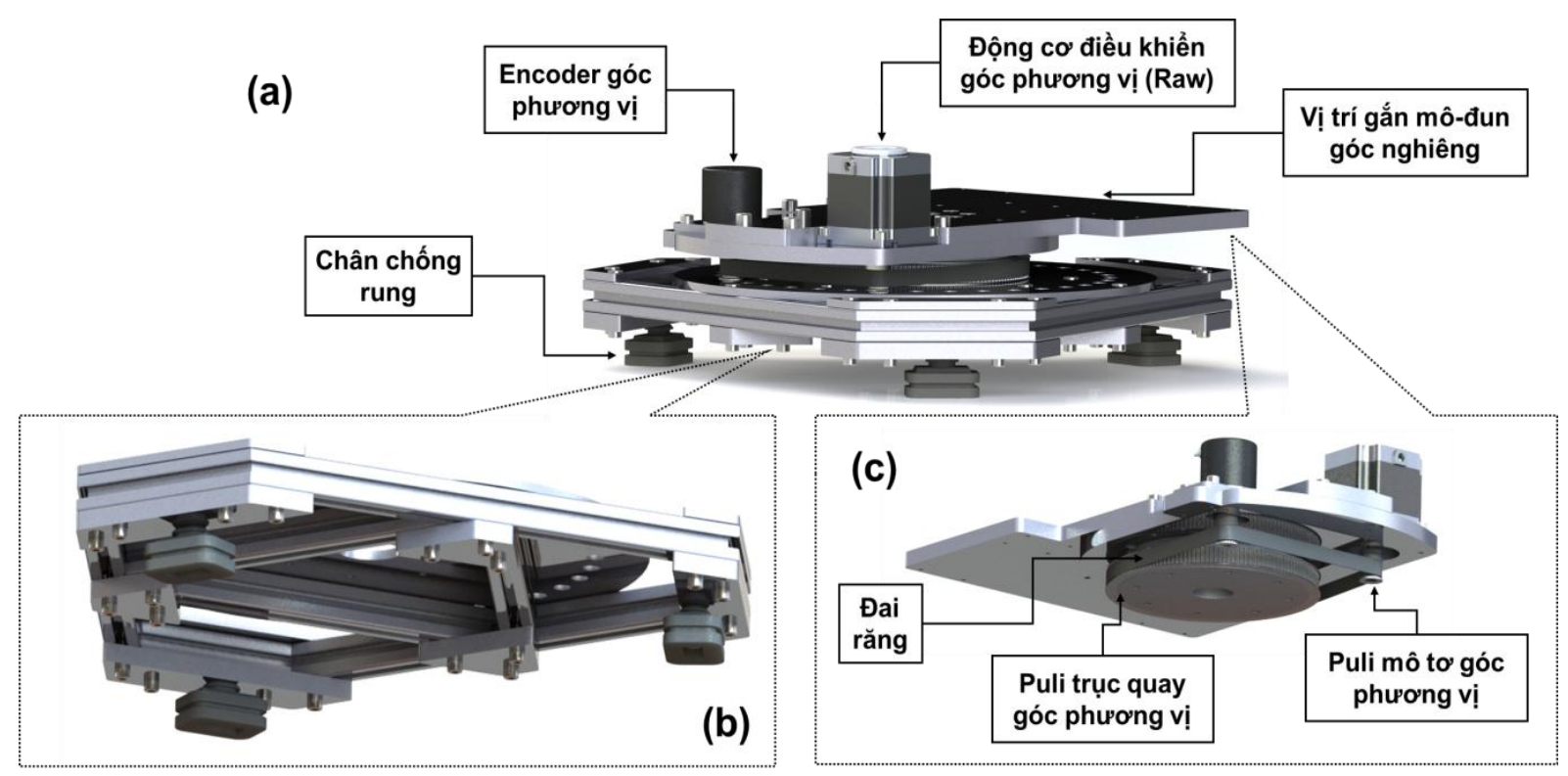

Hình 13. Cơ cấu tổng thể (a), mặt dưới của cơ cấu (b) và phần tách rời cơ cấu truyền động của mô-đun trục quay góc phương vị (c). 


\subsection{Các co cấu bảo vệ}

Các cơ cấu bảo vệ giúp hệ thống hoạt động ổn định lâu dài trước các tác động của thời tiết và môi trường, đặc biệt trong sử dụng trên tàu biển được đặc biệt quan tâm lưu ý.

Về vật liệu chế tạo hệ thống, nhóm nghiên cứu đã sử dụng các vật liệu không từ tính để đảm bảo không gây nhiễu từ lền hệ thống cảm biến đo từ trường trong IMU, có độ bền cơ học cao, khả năng chịu ăn mòn bởi muối biển cao như arcrylic, nhôm được anode hóa, ốc vít bằng inox... Các hệ thống điều khiển, driver đều được đóng gói công nghiệp và giao tiếp thông qua các giắc cắm chuyên dụng.

Toàn bộ hệ thống được đặt trong một vỏ bảo vệ (chuông) kín làm bằng vật liệu arcrylic giúp hệ chỉ tương tác với môi trường bên ngoài thông qua các giắc cấp nguồn và trả về tín hiệu cho đầu thu giải mã, hạn chế tối đa các tác động từ môi trường và thời tiết bên ngoài nhưng không hấp thụ sóng điện tử để đảm bảo không làm suy hao cường độ tín hiệu khi đi qua lớp vỏ bảo vệ này.
Trong trường hợp thiết bị không được cấp điện để hoạt động (điều kiện thời tiết không phù hợp hoặc khi người sử dụng không dùng thiết bị), lúc này, hệ thống không được duy trì chế độ hãm bởi động cơ. Do vậy, sự rung lắc và dao động của hệ thống trong một thời gian dài do được lắp đặt trên tầu chuyển động liên tục sẽ dẫn đến nhiều nguy cơ cho các cơ cấu cơ khí. Giải pháp xử lý cho vấn đề này đã được sử dụng nhờ cơ chế bảo vệ bằng chốt từ hoạt động dựa theo cơ chế của nam châm điện, khi ngắt điện hệ thống, các cuộn dây mất từ tính sẽ không hút chốt từ (thanh kim loại có từ tính) sẽ nhả ra và, thông qua cơ cấu lò xo đẩy các chốt vào khóa đĩa quay của các trục chuyển động. Khi điện được cấp lại, các cuộn dây sinh ra từ trường sẽ hút các thanh từ, rút các chốt ra khỏi vị trí khóa để hệ thống hoạt động bình thường. Qua các nghiên cứu và thử nghiệm thực tế, đây là giải pháp tối ưu và phù hợp nhất với các biên độ dao động của tàu.

Ảnh chụp toàn bộ hệ thống sau khi được gia công và lắp ráp hoàn thiện được đưa ra trên Hình 14.

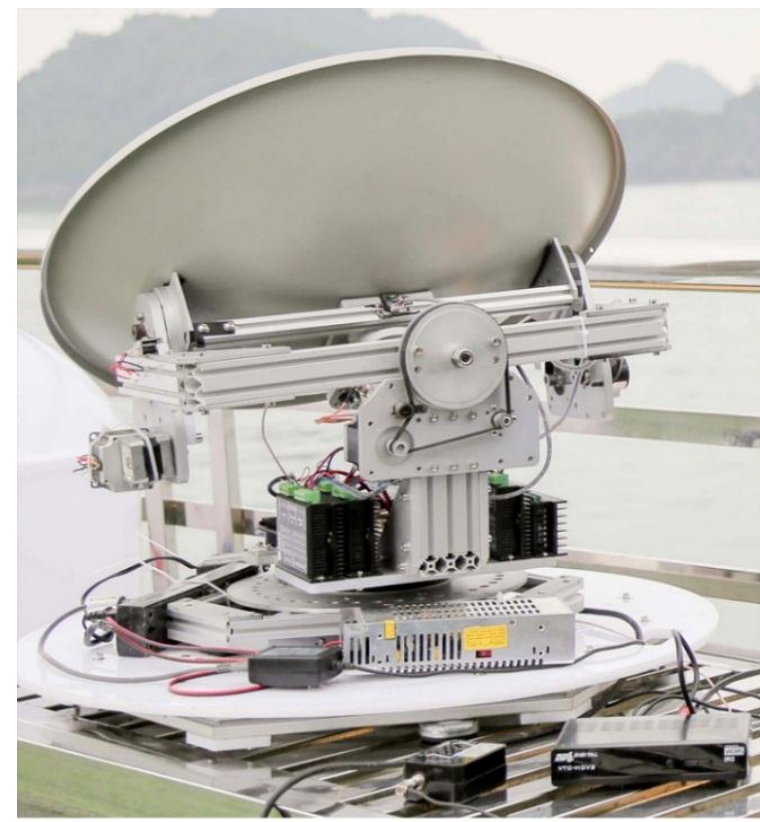

(a)

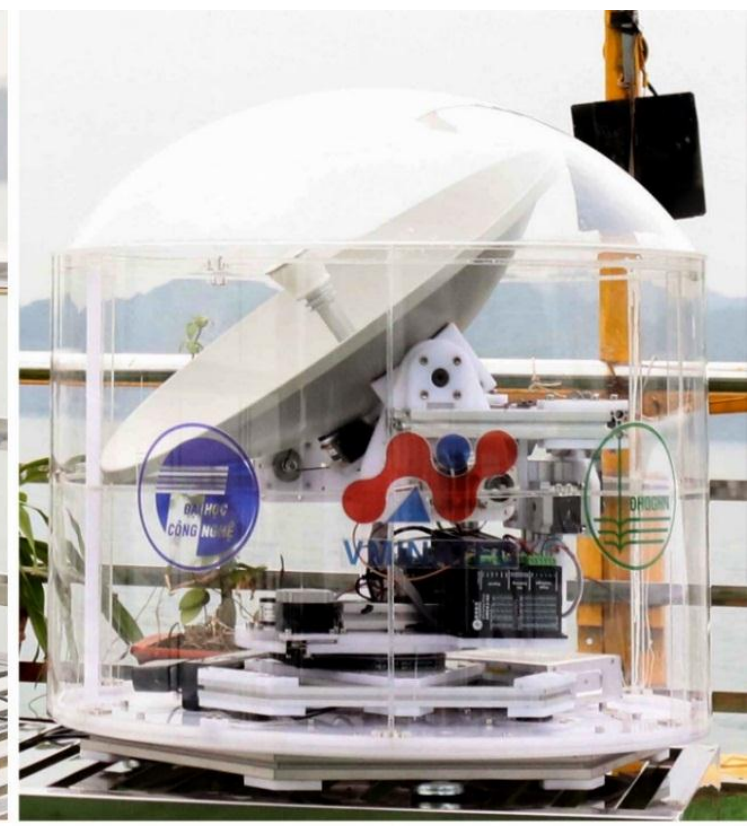

(b)

Hình 14. Ảnh chụp toàn bộ hệ thống sau khi được gia công và lắp ráp hoàn thiện khi chưa (a) và sau khi đậy nắp bảo vệ (b). 


\section{Thuật toán điều khiển}

Trong hệ thống chế tạo thử trước đây, khi hệ thống hoạt động, khối cảm biến liên tục xác định thông tin thời gian thực về giá trị 3 vị trí góc của ăng-ten và khối điều khiển trung tâm làm nhiệm vụ tính toán độ lệch các góc này với giá trị chuẩn để đưa ra giá trị góc cần điều khiển của mỗi môđun; đưa chảo ăng-ten về vị trí góc chuẩn ban đầu, đáp ứng sự thay đổi thời gian thực của hướng chảo ăng-ten. Điều này đồng nghĩa với việc thuật toán điều khiển phụ thuộc hoàn toàn vào tín hiệu cảm biến trả về. Do vậy, thuật toán trước đây chỉ hoạt động tốt khi sử dụng với các cảm biến có độ tin cậy cao, đồng nghĩa với giá thành rất lớn, có thể chiếm tới $30-50 \%$ chi phí sản xuất của cả thiết bị. Mặt khác, để xác định điểm làm việc ban đầu cho chảo ăng-ten, tàu biển cần được neo đậu tĩnh để tiến hành dò tìm vệ tinh, sau đó lưu lại trạng thái trả về của các cảm biến và bám theo các thông số đó; yêu cầu người sử dụng chảo phải có kiến thức và kỹ năng chuyên môn. Hơn thế nữa, trong trường hợp đã lưu lại các tham số để dò tìm được vệ tinh, thì việc phát sinh sai số của cảm biến sau một quá trình sử dụng sẽ dẫn tới việc bám góc bị sai và không thể duy trì trạng thái tín hiệu liên tục.

Giải pháp cho các vấn đề trên sẽ được sử dụng trên trạm thu di động phiên bản mới này nhờ tích hợp thêm với mô-đun đo cường độ tín hiệu vệ tinh để trả về cho hệ thống điều khiển đa điểm trung tâm MCU (multi control unit). Môđun này hoạt động như một "cảm biến cường độ tín hiệu" (signal strength sensor) kết hợp với hệ thống cảm biến tích hợp đo vị trí 3 góc của chảo ăng-ten là Roll, Pitch, Yaw và góc phân cực trong quá trình hoạt động. Tổ hợp các tín hiệu này sẽ được sử dụng làm tín hiệu đầu vào để điều khiển cơ cấu chấp hành của chảo ăng-ten. Sơ đồ chức năng và cấu trúc mạch điều khiển được đưa ra trên Hình 15 . Với giải pháp này, các vấn đề gặp phải về sai số của cảm biến sẽ được phát hiện và bù trừ nhờ tích hợp khối đo cường độ này. Nhờ đó, cho phép hệ thống sử dụng được các cảm biến thương mại với chi phí thấp hơn và đặc biệt do chế độ tự động dò cường độ này mà qui trình khởi động vận hành hệ thổng đơn giản và cho chất lượng tín hiệu thu được tốt hơn.

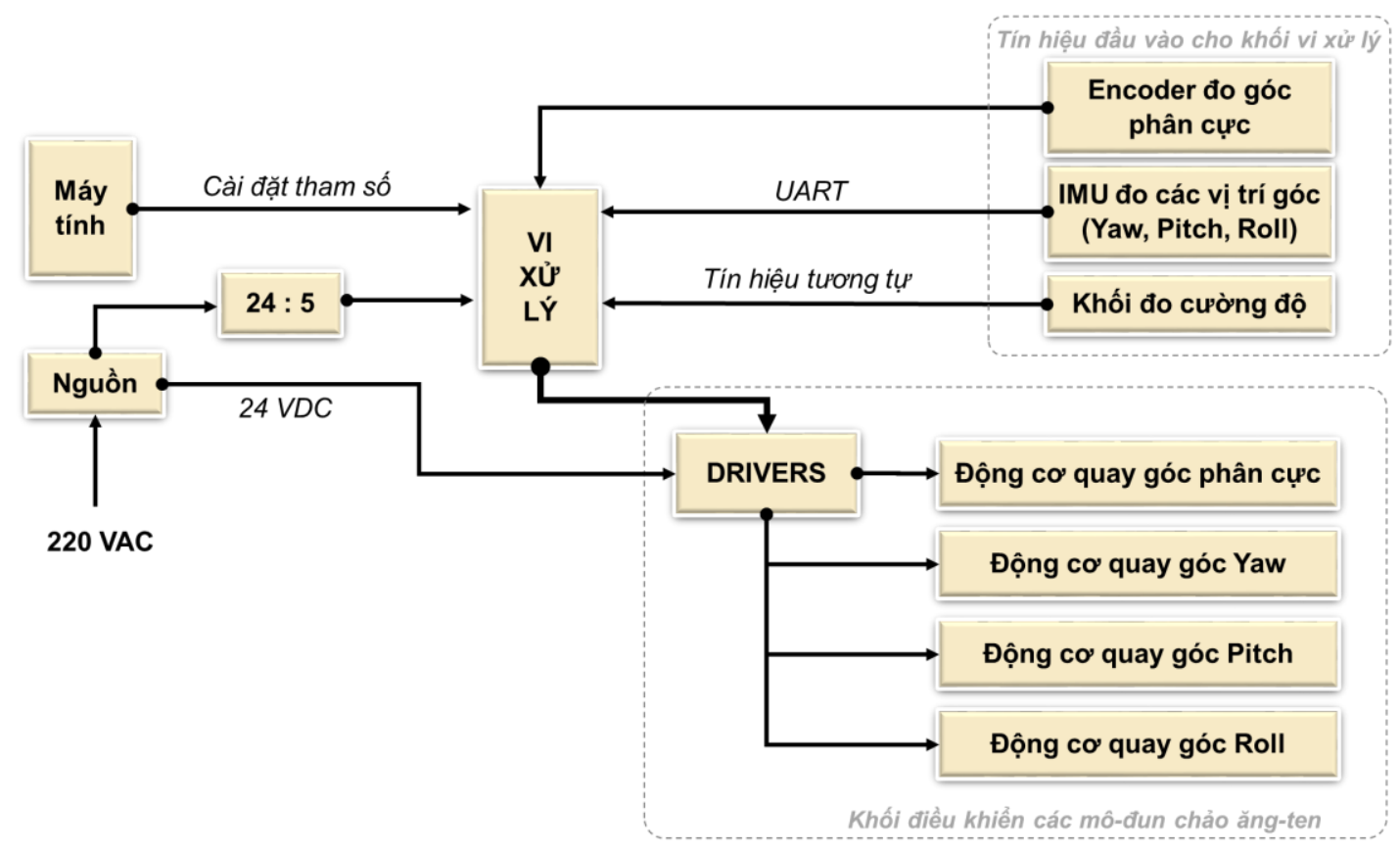

Hình 15. Sơ đồ chức năng và cấu trúc mạch điều khiển trung tâm. 
Hình 16 miêu tả cơ bản thuật toán được sử dụng trong điều khiển và vận hành hệ chảo thu tín hiệu vệ tinh gồm 2 vòng lặp. Khi khởi động hệ thống, thông số được nạp vào cho vị trí bám hướng của chảo ăng-teng là vị trí tham chiếu $\left(\varphi_{0}\right.$, $\left.\beta_{0}, \alpha_{0}\right)$ hay được hiểu là vị trí mà ở đó chảo thu hướng chính xác đến vị trí của vệ tinh. Khi đó, về mặt lý thuyết, cường độ tín hiệu mà chảo ăngten thu được sẽ là cực đại. Các vị trí góc này được xác định bởi các cảm biến của IMU và thông qua thuật toán PID để điều khiển hệ chảo bám hướng theo tọa độ vệ tinh được nạp vào ban đầu này. Trong trường hợp khi chảo ăng-ten đã được định hướng theo các tham số tham chiếu đầu vào nhưng cường độ tín hiệu không đạt giá trị cho phép được xác định bởi công thức $I<I_{0}$ với $I_{0}=0.9 I_{\max }$ thường xảy ra khi hệ thống cảm biến IMU mắc phải sai số số dẫn đến đến giá trị đo lường vị trí của ăng-ten không chính xác, khi đó, hệ thống sẽ thực hiện thuật toán kiểm tra cường độ tín hiệu để dò tìm vi trí vệ tinh và chuẩn hóa, đưa thông số tham chiểu về vị trí chuẩn nhất.

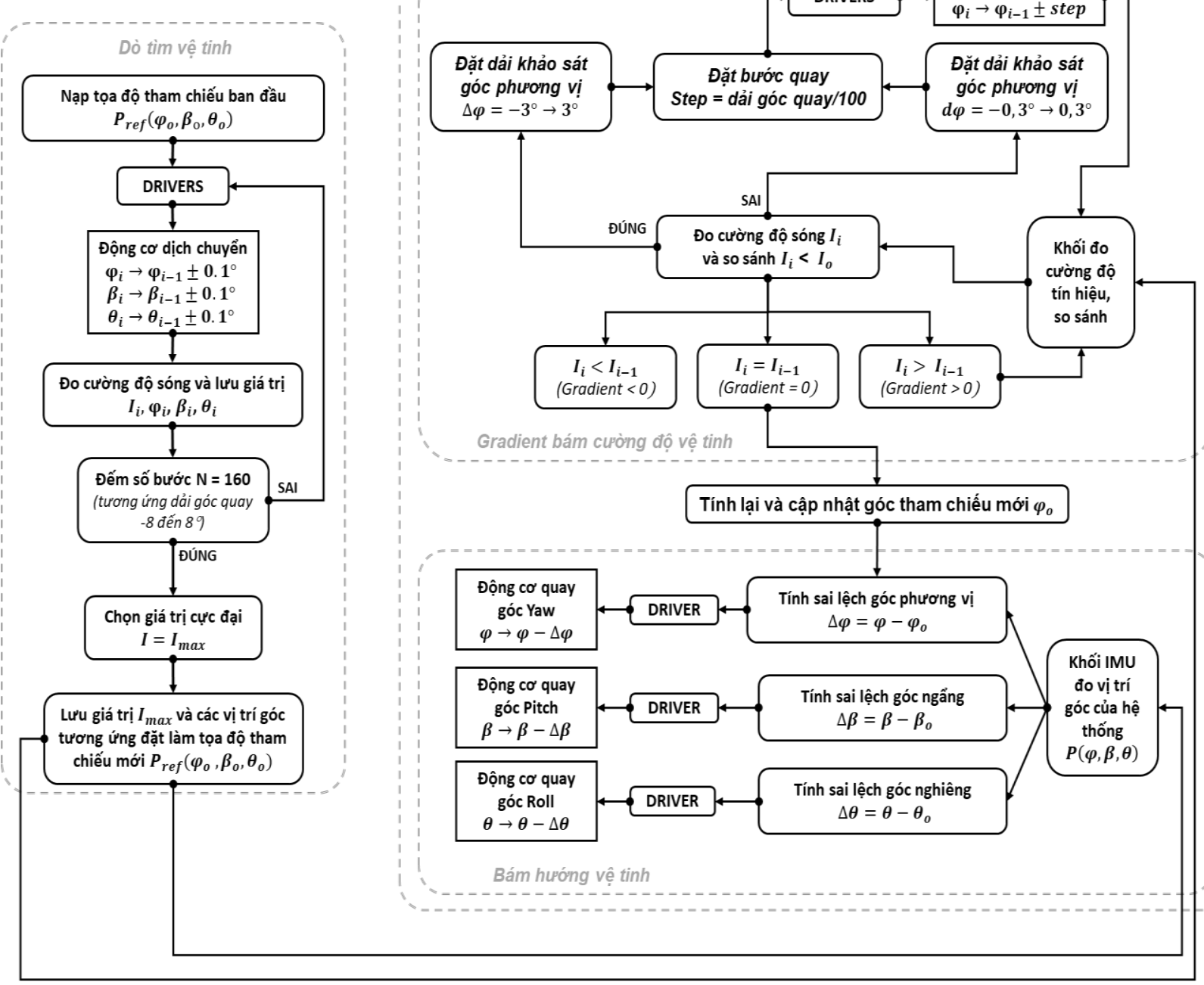

Hình 16. Sơ đồ thuật toán điều khiển chảo ăng-ten. 


\subsection{Thuật toán dò tìm vệ tinh dụa trên tụ động dò cuờng độ tín hiệu}

Sau khi hệ đầu thu được cấp nguồn điện, dựa vào vị trí đã được lưu từ lần hoạt động trước mạch điều khiển sẽ điều khiển các động cơ để đưa hệ về đúng với góc chính xác thu được tín hiệu tốt nhất ở phiên hoạt động trước. Tiếp theo đó cảm biến đo cường độ sẽ tiến hành đo đề kiểm tra mức độ tín hiệu hiện tại sau khi khởi động. Cảm biến cường độ sẽ liên tục ghi lại những thay đổi về cường độ của tín hiệu thu được trong khi hệ sẽ được mạch điều khiển để thăm dò các vị trị gần với vị trí tọa độ gốc ban đầu. Hai góc được điều khiển trong vòng lặp dò tìm vệ tinh là góc phương vị và góc ngẩng được quét đồng thời với dải quay góc ngẩng $\Delta \varphi=-6 \div 6^{\circ}$, dải quay góc phương vị $\Delta \beta=-8 \div 8^{\circ}$ tốc độ $2 \%$ giây. Mạch điều khiển hệ vừa tạo dao động vừa ghi lại cường độ tín hiệu và được điều khiển theo hướng quay làm cường độ tín hiệu vệ tinh tăng lên $(\Delta I>0)$. Tại vị trí chảo ăng-ten với cường độ tín hiệu vệ tinh đạt được cực đại sẽ được IMU ghi nhận là vị trí tham chiếu mới cho vòng lặp bám hướng vệ tinh của thuật toán. Qua kiểm nghiệm chạy thực tế, vị trí góc tham chiếu được lưu lại giữa các lần có sai số nhỏ (dưới $10^{\circ}$ ) do vậy với các thông số được thiết lập cho vòng lặp này, đảm bảo chảo ăng-ten luôn dò tìm vệ tinh với thời gian đáp ứng nhanh, duy trì tín hiệu liên tục.

\subsection{Thuật toán điều khiển hệ bám huớng vệ tinh}

Thuật toán này sử dụng tín hiệu đầu vào thu được từ cảm biến để tính toán độ sai lệch vị trí góc, đưa ra lệnh điều khiển động cơ trả vị trí chảo ăng-ten về vị trí tham chiếu chuẩn đã được nạp vào hệ thống. Khi vận hành trong điều kiện có sự thay đổi liên tục về vị trí của chảo thu so với vệ tinh, cảm biến gia tốc được sử dụng để thực hiện chức năng liên tục phân tích và ghi lại những thay đổi của ba góc là góc phương vị, góc ngẩng và góc nghiêng bao gồm cả giá trị, tốc độ thay đổi nhanh/chậm và chiều thay đổi. Thông thường, các góc này thay đổi với gia tốc, thời gian và biên độ rất khác nhau nên cần thông qua thuật toán xử lý PID để phản hồi thích hợp những thay đổi này. Mạch điều khiển dựa vào những sai lệch góc đo được từ cảm biến để điều khiển động cơ khử đi những sai lệch đó để đảm bảo tín hiệu thu được luôn nằm trong vùng hiệu dụng.

\subsection{Tự động chuẩn hóa góc tham chiếu theo thuật toán gradient bám hướng vệ tinh}

Cảm biến được sử dụng trong hệ thống là cảm biến tích hợp IMU gồm 3 khối cảm biến từ (đo phương vị), khối cảm biến gia tốc và khối cảm biến quán tính (đo góc ngẩng và góc nghiêng). Do nguyên lý hoạt động của cảm biến cũng như qua khảo sát thực tế thì cảm biến này thường có xảy ra sai số sau một thời gian sử dụng. Thời gian càng dài thì sai số sẽ càng lớn và thông thường, sẽ phải chuẩn hóa cảm biến định kỳ (calibration) để đảm bảo cảm biến hoạt động chính xác, đáp ứng độ tin cậy của các phép đo. Chính các sai số này của cảm biến dẫn đến sự sai lệch hướng của chảo ăng-ten so với hướng vệ tinh trong qúa trình bám hướng nếu hệ thống tin cậy hoàn toàn vào giá trị cảm biến để điều khiển bám hướng. Khảo sát thực tiễn trên cảm biến IMU được sử dụng trong hệ thống, sai số góc lớn nhất gặp phải với góc đo phương vị (do nhiễu loạn từ trường ảnh hưởng đến hoạt động của khối cảm biến từ) trong khi đó, với góc đo ngẩng và nghiêng thì giá trị này rât nhỏ $(\sim 0.2$ độ) sau một thời gian chạy thử. Do vậy, nếu hệ thống hoạt động trong thời gian dài và không có qui trình chuẩn hóa cảm biến thì trong thuật toán điều khiển bám hướng, với góc ngẩng và góc nghiêng thì hệ thống sẽ hoạt động tốt và bám chính xác hướngkhi điều khiển hoàn toàn dựa theo giá trị góc do cảm biến trả về. Riêng với góc phương vị, trong thuật toán điều khiển bám hướng, giải pháp tích hợp với thuật toán gradient để điều khiển, đảm bảo bám hướng chính xác kể cả trong trường hợp cảm biến gặp phải sai số với góc này.

Cơ sở khoa học của thuật toán gradient có thể được giải thích đơn giản là khi chảo ăng-ten đang được điều khiển quay theo một chiều xác định (tăng hoặc giảm) từ góc $\varphi$ sang góc $\varphi+\Delta \varphi$ để 
bám hướng vệ tinh thì chiều quay này sẽ là chiều quay đúng khi cường độ tín hiệu được ghi nhận bởi cảm biến đo cường độ sóng tăng lên $I(\varphi+\Delta \varphi)>I(\varphi)$. Mối liên hệ này có thể được biểu diễn dưới dạng hàm toán học:

$$
\frac{\Delta I}{\Delta \varphi}=\frac{I(\varphi+\Delta \varphi)-I(\varphi)}{\Delta \varphi}>0
$$

Khi bước quay $\Delta \varphi$ nhỏ thì biểu thức trên có thể được viết lại dưới dạng gradient của cường độ sóng theo biến góc phương vị như sau:

$$
I^{\prime}(\varphi)=\frac{d I(\varphi)}{d \varphi}=\lim _{\Delta \varphi \rightarrow 0} \frac{I(\varphi+\Delta \varphi)-I(\varphi)}{\Delta \varphi}>0
$$

Có thể áp dụng một công thức gần đúng với đủ nhỏ trong điều kiện thực nghiệm:

$$
\begin{aligned}
& I^{\prime}(\varphi)=\frac{d I(\varphi)}{d \varphi} \\
& =\lim _{\Delta \varphi \rightarrow 0} \frac{I(\varphi+\Delta \varphi)-I(\varphi-\Delta \varphi)}{2 \Delta \varphi}>0
\end{aligned}
$$

Cách tính này được gọi là gradient số (numerical gradient), trong đó, $I(\varphi+$ $\Delta \varphi)$ và $I(\varphi-\Delta \varphi)$ dễ dàng có được bằng cách đọc trực tiếp giá trị từ cảm biến đo cường độ tín hiệu. Khi giá trị $I^{\prime}(\varphi)=0$ thì vị trí chảo ăng-ten đang hướng đúng theo vệ tinh, tại đó, cường độ tín hiệu thu nhận được từ vệ tinh đạt giá trị cực đại. Đây sẽ là góc phương vị tham chiếu mới $\varphi_{o}$ được lưu vào hệ thống.

\section{Kết quả thử nghiệm}

Qui trình thử nghiệm thiết bị được tiến hành theo 2 bước:

Bước 1: Thử nghiệm trong phòng thí nghiệm, hệ thống được lắp ráp trên các cơ cấu chấp hành cơ khí giả chuyển động của sóng biển

Bước 2: Thử nghiệm trong điều kiện dã ngoại, hệ thống được lắp ráp trên tầu biển và chạy thử nghiệm trên biển.

\subsection{Thủ nghiệm trong phòng thí nghiệm}

Để thực hiện được chạy thử trong phòng thí nghiệm với điều kiện giống như chạy thật, một hệ thống tạo dao động 4 bậc tự do 4DOF (4 degrees of fredom) đã được thiết kế, gia công và chế tạo như được đưa ra trên Hình 17.

Chương trình điều khiển cho hệ thống tạo dao động giống dao động của tầu thuyền được thực hiện trên cơ sở ghi nhận dạng dao động của tàu di chuyển theo thời gian trong các điều kiện khác nhau sử dụng hệ thống cảm biến đo góc để đo. Từ dữ liệu thu thập được, thuật toán sẽ được xây dựng để giả lập lại các dạng dao động này để nạp vào hệ dao động $4 \mathrm{DOF}$ đã được chế tạo. Các thông số được nạp cho hệ thống với dải hoạt động của góc phương vị $0-360^{\circ}$, dải hoạt động của góc ngẩng $15-80^{\circ}$, dao động với tốc độ tối đa $12 \%$ và gia tốc khoảng $12 \% \mathrm{~s}^{2}$. Bước thử nghiệm trong phòng thí nghiệm này rất cần thiết, giúp cho tối ưu hoạt động hệ thống chảo ăng-ten khi chạy thử trong PTN giúp kịp thời xử lý, tiết kiệm thời gian, công sức và chi phí.

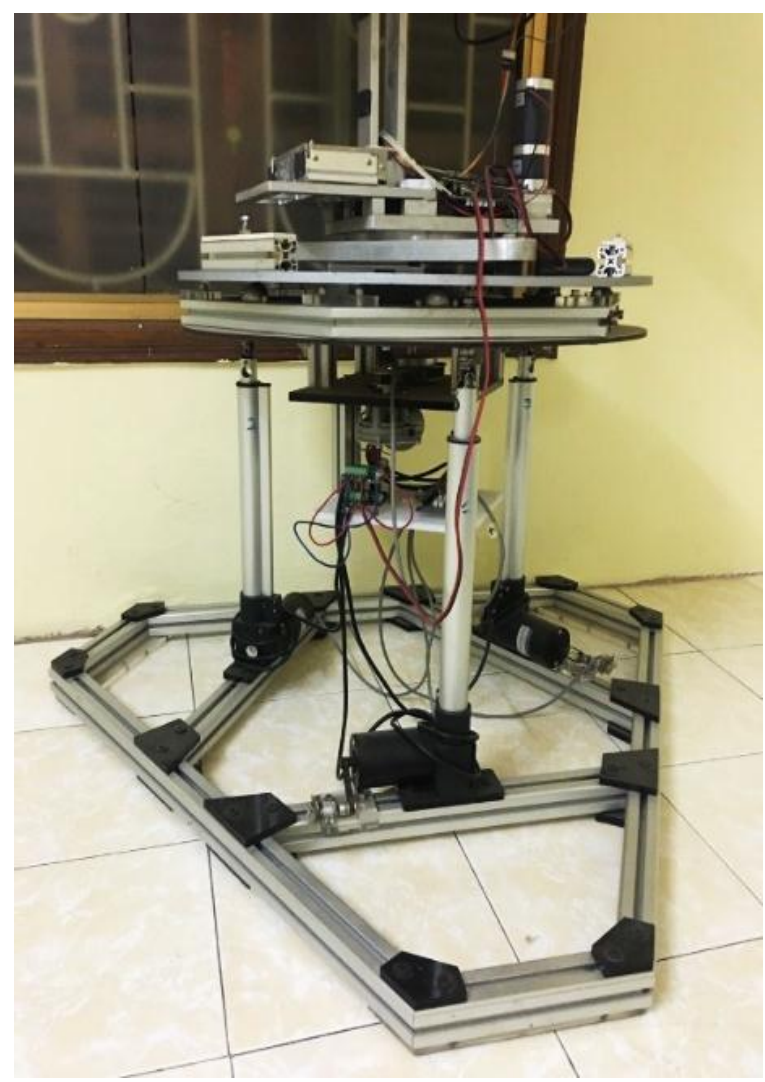

Hình 17. Hệ 4DOF dùng để giả lập trạng thái trên tàu biển. 


\subsection{Thư nghiệm trên biển}

Hệ thống sau khi được chế tạo hoàn thiện đã được lắp đặt trên tàu du lịch trọng tải 45 tấn, dài $19 \mathrm{~m}$, rộng 4,5 m và chạy thử nghiệm nhiều lần, trong nhiều ngày liên tục vớinhiều điều kiện khác nhau trên vùng biển thị trấn Cát Bà - Hải Phòng (Hình 18). Kết quả chạy thử nghiệm trên 03 hệ thống chảo thu ăng-ten cho tín hiệu truyền hình thu được đã đảm bảo độ ổn định, suy trì liên tục và được các chuyên gia trong tổ thẩm định đánh giá cao.

Các thông số kỹ thuật đã thử nghiệm là:
- Tín hiệu truyền hình vệ tinh VINASAT 2, băng tần $\mathrm{Ku}$

- Ăng ten: đường kính 24"

- EIRP tối thiểu: 74dbW

- Phạm vi hoạt động góc ngẩng: $15-80^{\circ}\left( \pm 0,5^{\circ}\right)$

- Phạm vi hoạt động góc phương vị: 0 - 360 $\left( \pm 0,25^{\circ}\right)$

- Tốc độ quay góc của ăng-ten : 12\%/s.

- Gia tốc độ quay góc của ăng-ten : $12 \% \mathrm{~s}^{2}$.

- Tốc độ của tầu: $30 \mathrm{~km} / \mathrm{h}$ khi thời tiết bình thường, gió nhẹ cấp 3 .

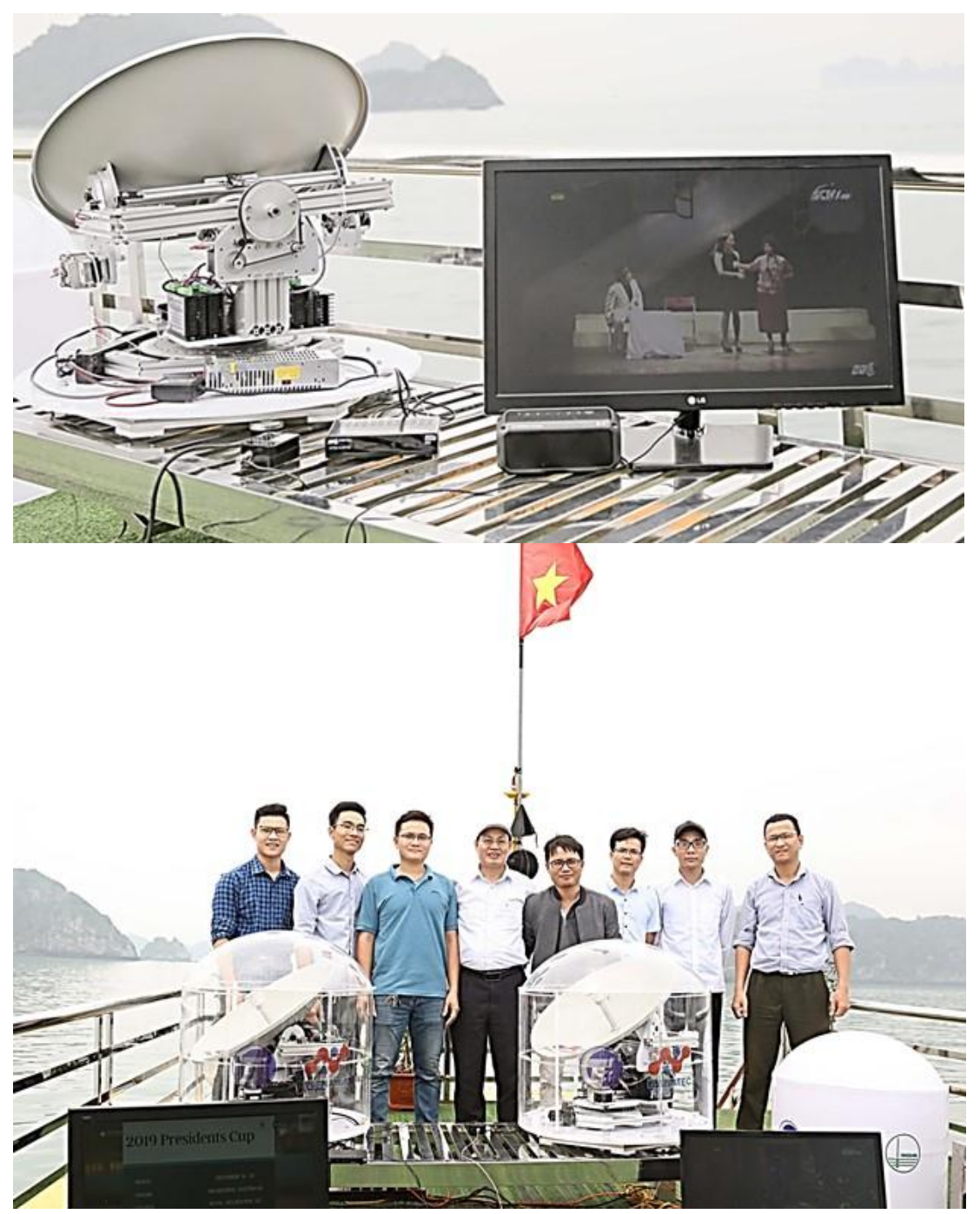

Hình 18. Nhóm thực hiện đề tài chạy thử nghiệm thiết bị trên vùng biển Cát Bà. 


\section{Kết luận}

Hệ thống trạm thu di động thông tin vệ tinh thế hệ thứ hai đã được nhóm nghiên cứu phát triển thiết kế, chế tạo và lắp ráp hoàn chỉnhsử dụng các mô-đun cơ khí chế tạo tại Việt Nam, các cảm biến tích hợp, mô tơ và driver thương mại. Đặc biệt, nhóm nghiên cứu đã chủ động xây dựng các thuật toán và phần mềm điều khiển hợp lý, đáp ứng yêu cầu tự động dò tìm và bám hướng vệ tinh của chảo ăng-ten. Các cơ cấu chấp hành được thiết kế và gia công cơ khí đáp ứng độ chính xác cao sử dụng các vật liệu không từ, không bị oxy hóa vàtất cả các hệ thống bao gồm mạch điện tử, linh kiện được đóng gói để đảm bảo an toàn cho hệ thống khi được lắp ráp trên tầu biển, làm việc liên tục trong môi trường có độ mặn cao.

Các thông số kỹ thuật chính của thiết bị đã chế tạo thành công được thể hiện trong bảng 1 .

Bảng 1. Thông số kỹ thuật của trạm thu di động tín hiệu vệ tinh

\begin{tabular}{|c|c|}
\hline Nội dung & Thông số \\
\hline \multicolumn{2}{|l|}{ Kích thước: } \\
\hline - Đường kính chảo ăng ten & $24 " '(610 \mathrm{~mm})$ \\
\hline - Kích thước tổng thể & $720 \mathrm{~mm}$ X $720 \mathrm{~mm}$ X $785 \mathrm{~mm}$ \\
\hline Khối lượng & $18 \mathrm{~kg}$ \\
\hline \multicolumn{2}{|l|}{ Điều kiện làm việc: } \\
\hline - Nhiệt độ & $0^{\circ} \mathrm{C}-55^{\circ} \mathrm{C}$ \\
\hline - Độ ẩm & $0 \%-95 \%$ \\
\hline Điện áp & $220 \mathrm{VAC} / 50 \mathrm{~Hz}$ \\
\hline Điện năng tiêu thụ & $30 \mathrm{~W}-50 \mathrm{~W}$ \\
\hline \multicolumn{2}{|l|}{ Đáp ứng của hệ thống } \\
\hline - Dải tần & $\mathrm{Ku}(12 \mathrm{GHz}-18 \mathrm{GHz})$ \\
\hline - EIRP tối thiểu & $74 \mathrm{dbW}$ \\
\hline - Phạm vi hoạt động góc phương vị & $0-360^{\circ}\left( \pm 0,25^{\circ}\right)$ \\
\hline - Phạm vi hoạt động góc ngẩng & $15-80^{\circ}\left( \pm 0,5^{\circ}\right)$ \\
\hline - Tốc độ quay góc của ăng-ten & $\sim 12 \% \mathrm{~s}$ \\
\hline - Gia tốc độ quay góc của ăng-ten & $\sim 12^{\circ} / \mathrm{s}^{2}$ \\
\hline
\end{tabular}

Thiết bị được sản xuất trong nước có giá thành thấp hơn so với hệ thống nhập khẩu, cùng với việc làm chủ công nghệ lõi hứa hẹn khả năng hợp tác chuyển giao công nghệ sản xuất cho các cơ sở doanh nghiệp trong nước với chi phí thấp hơn để đáp ứng nhu cầu to lớn của thị trường đóng tầu trong nước trong giai đoạn hiện nay.

\section{Lời cảm ơn}

Công trình này là sản phẩm của đề tài KH\&CN cấp ĐHQGHN mã số QG. 16. 89.

\section{Tài liệu tham khảo}

[1] B. Schneiderman, Executive Roundtable on Maritime and Energy Markets, Satellite Executive Briefing 11 (8) (2018) 9.

[2] L.M. Bradbury, D. Diaconu, S. Molgat Laurin, A.M. Beattie, C. Ma, I.S. Spydevold, H.C. Haugli, R.E. Zee, J. Harr, F. Udnæs, NorSat-2: Enabling advanced maritime communication with VDES, Acta Astronautica 156 (2019) 44-50.

[3] Y.J. Song, P.S. Kim, D.G. Oh, et al., Development of mobile broadband interactive satellite access system for $\mathrm{Ku} / \mathrm{Ka}$ band, International journal of satellite communications and networking 24 (2007) 101-117. 
[4] Y.J. Song, M.S. Shin, B.H. Kim, et al, Development of mobile broadband satellite access system for $\mathrm{Ka} / \mathrm{Ku}$-band satellite communications, Ieice transactions on communications, e87b (2004) 2152-2161.

[5] S. Pekowsky, G Pousset, Y. Levy, MobileTV Receiver Technology with special emphasis on DVB-SH, international journal of satellite communications and networking 27 (2009) 275-293.

[6] http://www.raysat.com/mobile_satellite_television _antennas.

[7] Nguyễn Hữu Đức, Bùi Đình Tú, Nguyễn Thị Ngọc, Đồng Quốc Việt, Đỗ Thị Hương Giang, Trạm thu di động thông tin vệ tinh dựa trên sensơ từ trường độ nhạy cao ứng dụng trên tàu biển, Tuyển tập Hội thảo khoa học Công nghệ vũ trụ và ứng dụng, Hà Nội, 2014.
[8] M. Geissler, F. Woetzel, M.Böttcher, S. Korthoff, A.Lauer, M.Eube, R. Gieron, Roman, Innovative phased array antenna for maritime satellite communications, EuCAP 2009. 3rd European Conference on Antennas and Propagation 2009, pp.735-739.

[9] http://www.orbit-cs.com/modular-maritimecommunications-system

[10] https://www.digisat.org/maritime-satcom-vsat

[11] https://paracomm.co.uk/

[12] https://www.intelliantech.com/?lang=en.

[13] Nguyễn Hữu Đức, Báo cáo tổng kết đề tài đề tài "Thiết kế và chế tạo trạm thu di động thông tin vệ tinh dựa trên sensơ từ trường độ nhạy cao ứng dụng trên tàu biển", Chương trình KH\&CN quốc gia về Công nghệ vũ trụ giai đoạn 2013-2015, Hà Nội, 2016. 